\title{
Potential Vorticity Structure in the North Atlantic Western Boundary Current from Underwater Glider Observations
}

\author{
ROBERT E. TODD AND W. BRECHNER OWENS \\ Woods Hole Oceanographic Institution, Woods Hole, Massachusetts \\ DANIEL L. RUDNICK \\ Scripps Institution of Oceanography, University of California, San Diego, La Jolla, California
}

(Manuscript received 24 June 2015, in final form 10 November 2015)

\begin{abstract}
Potential vorticity structure in two segments of the North Atlantic's western boundary current is examined using concurrent, high-resolution measurements of hydrography and velocity from gliders. Spray gliders occupied 40 transects across the Loop Current in the Gulf of Mexico and 11 transects across the Gulf Stream downstream of Cape Hatteras. Cross-stream distributions of the Ertel potential vorticity and its components are calculated for each transect under the assumptions that all flow is in the direction of measured vertically averaged currents and that the flow is geostrophic. Mean cross-stream distributions of hydrographic properties, potential vorticity, and alongstream velocity are calculated for both the Loop Current and the detached Gulf Stream in both depth and density coordinates. Differences between these mean transects highlight the downstream changes in western boundary current structure. As the current increases its transport downstream, upper-layer potential vorticity is generally reduced because of the combined effects of increased anticyclonic relative vorticity, reduced stratification, and increased cross-stream density gradients. The only exception is within the 20-km-wide cyclonic flank of the Gulf Stream, where intense cyclonic relative vorticity results in more positive potential vorticity than in the Loop Current. Cross-stream gradients of mean potential vorticity satisfy necessary conditions for both barotropic and baroclinic instability within the western boundary current. Instances of very low or negative potential vorticity, which predispose the flow to various overturning instabilities, are observed in individual transects across both the Loop Current and the Gulf Stream.
\end{abstract}

\section{Introduction}

The Loop Current in the Gulf of Mexico and the Gulf Stream along the east coast of North America are segments of the North Atlantic's western boundary current. As part of the Atlantic meridional overturning circulation, they are responsible for transferring heat from the tropics to higher latitudes (e.g., Cunningham et al. 2007). The western boundary current is also a major source of the kinetic energy (e.g., Wyrtki et al. 1976) that stirs the ocean across a range of scales, many of which are poorly resolved by global-scale numerical models. Understanding the structure and behavior of the western boundary current is a key problem in climate dynamics. However, despite

Corresponding author address: Robert E. Todd, Department of Physical Oceanography, Woods Hole Oceanographic Institution, 266 Woods Hole Rd., Mail Stop \#21, Woods Hole, MA 02543. E-mail: rtodd@whoi.edu observational evidence in recent years of the western boundary current deviating outside established meander envelopes (Gawarkiewicz et al. 2012; Ezer et al. 2013), ongoing debates over possible recent changes in Gulf Stream transport (Ezer et al. 2013; Rossby et al. 2014), and forecasts of changes in the meridional overturning as a consequence of anthropogenic climate change (e.g., IPCC 2007, and references therein), there remain many unknowns about the structure and variability of the western boundary current under the current climate.

An important dynamical quantity in the western boundary current is the potential vorticity, which was originally conceived by Ertel (1942a; Schubert et al. 2004). The potential vorticity $Q$ may be written as

$$
Q=-\frac{2 \boldsymbol{\Omega}+\zeta}{\rho} \cdot \nabla \rho_{\theta},
$$

where $2 \boldsymbol{\Omega}$ represents the earth's axis of rotation, $\boldsymbol{\zeta}$ is the relative vorticity, $\rho$ is the density, and $\rho_{\theta}$ is the potential 
density (Ertel 1942b). In the ocean interior, where the flow can be assumed to be adiabatic and inviscid, potential vorticity acts as a conserved tracer that is dynamically active. Near the surface, buoyancy and frictional forcing are sources of potential vorticity (Thomas 2005).

Potential vorticity can be used as a measure of stability in ocean currents and other geophysical flows. Barotropic instability can lead to meandering of the current when the cross-stream gradient of the absolute vorticity $(2 \boldsymbol{\Omega}+\boldsymbol{\zeta})$ changes sign (Holton 1979; Gill 1982). Baroclinic instability can occur when the sign of the cross-stream potential vorticity gradient changes with depth (Pedlosky 1964; Johns 1988). When the potential vorticity takes the opposite sign of the Coriolis parameter $f$, a flow is susceptible to a variety of overturning instabilities (Thomas et al. 2013); in the Northern Hemisphere, regions of negative potential vorticity are of interest since the Coriolis parameter is positive. As described by Thomas et al. (2013), these overturning instabilities may be due to large anticyclonic (vertical) relative vorticity (inertial or centrifugal instabilities), unstable stratification (gravitational instability), or large horizontal buoyancy and density gradients (symmetric instability). Each type of instability tends to homogenize the potential vorticity until stability is achieved; inertial instabilities result in horizontal stirring, gravitational instabilities result in vertical mixing, and symmetric instabilities result in along-isopycnal (slanted) stirring (Thomas 2007).

Previous studies in both the Gulf Stream and Loop Current have highlighted the role of potential vorticity in determining the stability of the western boundary current. Logoutov et al. (2001) reported a cross-stream potential vorticity gradient in the upper portion of the Gulf Stream $\left(\rho_{\theta}<27.3 \mathrm{~kg} \mathrm{~m}^{-3}\right)$ that satisfied the necessary condition for barotropic instability using observations from a free-falling velocity probe and shipboard hydrography. Thomas et al. (2013) observed negative potential vorticity and symmetric instability on the northern flank of the Gulf Stream in a combined SeaSoar and ADCP survey. In the Loop Current, Oey's (2004) analysis of moored observations across the Yucatan Channel (Candela et al. 2002) suggests that an influx of cyclonic potential vorticity tends to extend the Loop Current into the Gulf of Mexico while an influx of anticyclonic potential vorticity may trigger retraction and eddy shedding; this argument, however, does not account for the important contributions of cyclonic Loop Current frontal eddies in the eddy-separation process (e.g., Le Hénaff et al. 2012; Gopalakrishnan et al. 2013; Rudnick et al. 2015).

The Gulf Stream and its potential vorticity structure are also key to the formation of subtropical mode water in the North Atlantic. Subtropical mode waters are characterized by their low potential vorticity signature, which results from their vertical homogeneity and weak static stability (e.g., McCartney 1982). Eighteen Degree Water is the name given to the subtropical mode water in the North Atlantic (Worthington 1959) that is typically found at potential densities of about $26.5 \mathrm{~kg} \mathrm{~m}^{-3}$ (e.g., Worthington 1959; McCartney 1982). The need to understand the processes by which potential vorticity is reduced and mode waters are formed motivated the recent CLIVAR Mode Water Dynamic Experiment (CLIMODE) project (Marshall et al. 2009). Joyce et al. (2013) show that much of the newly formed Eighteen Degree Water is ventilated within the Gulf Stream during winter where a number of processes contribute to lowering the potential vorticity and forming mode water. Heat loss to the atmosphere erodes the seasonal stratification (Joyce et al. 2013); strong vertical shear (due to horizontal buoyancy gradients) makes the flow prone to symmetric instabilities (Joyce et al. 2009; Thomas et al. 2013); strong anticyclonic shear south of the core of the Gulf Stream lowers the absolute vorticity (Joyce et al. 2009); and down-front winds advect heavier waters over lighter waters (Thomas 2005; Thomas et al. 2013). The combination of these mechanisms can produce negative potential vorticity within the upper portion of the Gulf Stream (e.g., Joyce et al. 2009). Numerical investigations by Maze et al. (2013) show that diabatic and frictional (wind forced) fluxes of potential vorticity through the air-sea interface are of similar magnitude over the Gulf Stream region, but that frictional fluxes show much smaller spatial scales because of their dependence on surface density gradients. On the other hand, Olsina et al. (2013) suggest that buoyancy forcing dominates over frictional forcing on climatological scales.

Despite its importance, our understanding of the potential vorticity structure in the western boundary current remains incomplete because of difficulty in deducing the potential vorticity field from observations. Concurrent measurements of both velocity and hydrography across a flow are needed to calculate the potential vorticity according to Eq. (1) without neglecting important contributions. For example, the float studies by Bower (1989) and Song and Rossby (1997) could only measure the contributions of planetary vorticity and flow curvature. A scale analysis by Logoutov et al. (2001) suggests that when the relative vorticity is of comparable magnitude to the planetary vorticity, as it is in the western boundary current, station spacing must be on the order of $10 \mathrm{~km}$ to avoid underestimating the relative vorticity. Among the relatively few cases that have obtained the necessary measurements in the Gulf Stream are the 
combined Pegasus-CTD survey reported by Logoutov et al. (2001), the ship-based survey around Lagrangian floats described by Rajamony et al. (2001), and the SeaSoar observations collected during CLIMODE (Joyce et al. 2009; Thomas et al. 2013). These surveys are brief snapshots because of limitations imposed by using a ship. The Loop Current has generally been less heavily observed than the Gulf Stream, but a 2-yr time series of currents and density from a mooring array across the Yucatan Channel captures the potential vorticity flux into the Gulf of Mexico (Candela et al. 2002; Oey 2004).

The following analysis uses concurrent, highresolution hydrographic and velocity measurements from many glider transects across two segments of the North Atlantic western boundary current to examine cross-stream potential vorticity structure. The observations and methods for estimating potential vorticity from them are discussed in section 2. Section 3 considers representative transects from the Loop Current and Gulf Stream, compares mean hydrographic and velocity structure to previous efforts to demonstrate that the observations used here accurately represent persistent western boundary current structure, examines mean cross-stream potential vorticity structure for the first time, and uses the potential vorticity fields to consider the western boundary current's susceptibility to various instabilities. Section 4 summarizes the results, and the appendix considers potential errors in the mean fields.

\section{Observations and methods}

\section{a. Glider observations in the Gulf Stream and Loop Current}

This analysis uses observations of temperature, salinity, and velocity collected by Spray gliders (Sherman et al. 2001) crossing the Gulf Stream and Loop Current (Fig. 1). Like other autonomous buoyancy-driven gliders (Davis et al. 2003; Rudnick et al. 2004), Spray moves along a sawtooth path through the water, gliding forwards as it rises and falls by adjusting its volume. During the ascending portion of its flight, Spray measures temperature and salinity every $8 \mathrm{~s}$ with a pumped Seabird 41CP CTD instrument, resulting in profiles with vertical resolution smaller than $1 \mathrm{~m}$. Our analysis is conducted using data that have been bin averaged to a uniform vertical grid with $10-\mathrm{m}$ spacing. While underwater, Spray records pressure, pitch, and heading, which are used to estimate its horizontal displacement through the water; this dead-reckoned displacement is combined with GPS measurements at the surface to estimate vertically averaged water velocity during each dive with accuracy of approximately $0.01 \mathrm{~m} \mathrm{~s}^{-1}$ (Todd et al. 2011). Data are available by request, and plots are available at http://spray.ucsd.edu.

To collect the observations analyzed here, gliders were instructed to attempt to fly at right angles to the measured flow. The horizontal speed of a Spray glider through the water during normal flight is approximately $0.25 \mathrm{~m} \mathrm{~s}^{-1}$, much less than the (vertically averaged) speed of the western boundary current that regularly exceeds $1 \mathrm{~m} \mathrm{~s}^{-1}$. Consequently, gliders are advected downstream as they cross the current, resulting in typical crossing angles of $25^{\circ}-40^{\circ}$ to the left or right of the flow (e.g., Figs. 2a,b). Several features of Spray have allowed it to cross the Gulf Stream, Loop Current, and other strong boundary currents (e.g., Davis et al. 2012; Rudnick et al. 2013) with minimal operator intervention. By typically diving to a maximum depth of $1000 \mathrm{~m}$, gliders experienced modestly reduced vertically averaged currents compared to those that would be experienced by diving to a shallower depth. Typical endurance of 4 months per deployment allowed time for gliders to make upstream progress when away from the boundary current where currents were weak so that multiple transects could be occupied in the same region. Most significantly, Spray is able to operate in a currentcrossing navigation mode in which the glider automatically adjusts its heading after each dive to steer a fixed direction relative to measured vertically averaged currents. This mode allows the glider to continually make progress across a strong and variable current without operator intervention. Steering a constant heading or attempting to reach a predefined waypoint (with or without current correction) can easily lead to the glider attempting to swim directly into a strong current and requiring operator intervention.

Spray glider surveys across the Gulf Stream were conducted between fall 2004 and early 2009 (Fig. 1b), including the first crossings of a western boundary current by an autonomous underwater glider. A total of four glider deployments yielded 11 transects across the Gulf Stream downstream of Cape Hatteras, North Carolina, where the western boundary current is separated from the continental slope. Three deployments began at the shelf break south of Cape Cod $\left(\sim 40^{\circ} \mathrm{N}\right.$, $70^{\circ} \mathrm{W}$ ) while the other began at the shelf break off of Cape Fear, North Carolina $\left(\sim 34^{\circ} \mathrm{N}, 77^{\circ} \mathrm{W}\right)$. The first two deployments consisted of single transects from the continental margin to near Bermuda; the last two deployments repeatedly crossed the Gulf Stream before the gliders were recovered south of Cape Cod. During the deployment in early 2006, the Gulf Stream was in the process of shedding an unusually large warm core ring (see Cenedese et al. 2013). 

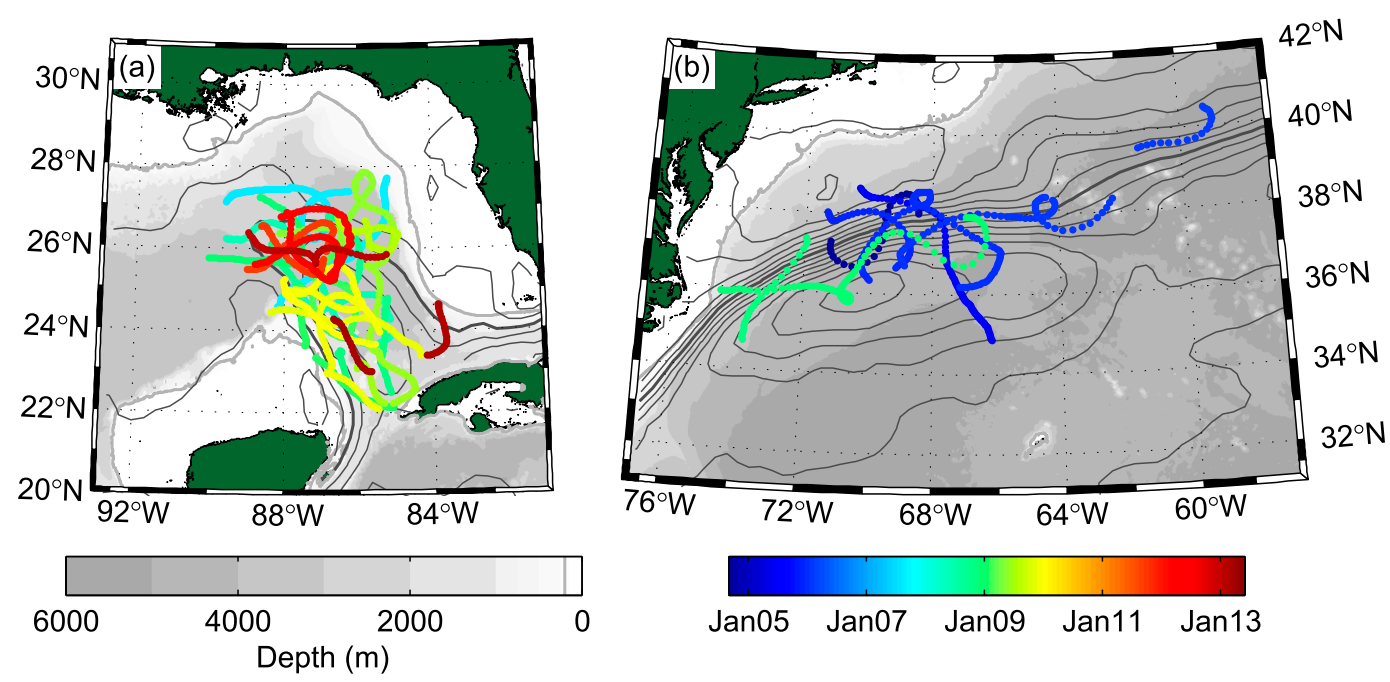

FIG. 1. Maps of Spray glider observations across the (a) Loop Current and (b) Gulf Stream. Individual dots indicate profile locations, with colors indicating date of sampling. Mean SSH during 2004-12 from the AVISO mapped absolute dynamic topography product is contoured every $10 \mathrm{~cm}$ and shows the mean location of the western boundary current as large gradients; the 40-cm contour, which tracks the path of the Loop Current and Gulf Stream well, is shown thick. Bathymetry is shaded gray; the edge of the continental shelf (i.e., 200-m isobath) is drawn in gray.

From mid-2007 through mid-2014, one or more Spray gliders were deployed nearly continuously in the eastern Gulf of Mexico. Gliders were typically deployed and recovered near the edge of the continental shelf offshore of the Mississippi River delta and navigated as far south as the Yucatan Channel and as far east as the entrance to Florida Strait. This analysis uses observations from a total of 40 transects across the Loop Current through spring 2013 (Fig. 1a). These transects captured the Loop Current in a variety of positions with its maximum northward extension varying roughly from $24^{\circ}$ to $27^{\circ} \mathrm{N}$; the Loop Current extends north of $24^{\circ} \mathrm{N}$ more than $90 \%$ of the time and extends beyond of $27^{\circ} \mathrm{N}$ less than $20 \%$ of the time (Vukovich 2007).

Several glider deployments prior to 2010 were plagued by poorly performing conductivity cells in the gliders' CTDs. Typically, conductivity measurements were anomalously low during portions of the deployment, resulting in low salinity estimates and often density profiles that were far from statically stable. Temperature and pressure measurements were unaffected. Density profiles are key to the analysis presented below, so we reconstructed salinity profiles as follows and then used the reconstructed salinity profiles with measured temperature and pressure to calculate density profiles. All full-resolution data from all deployments were first manually screened for obviously bad points. After this screening, several deployments exhibited a clear drift in conductivity that appeared as gradual freshening of deep waters. The climatology-based correction for drifting conductivity sensors of Owens and Wong (2009) was applied to the pre-2010 deployments, resulting in typical salinity adjustments of less than 0.1 but as large as 0.6 at the end of one deployment. Large gaps remained in salinity profiles from some Loop Current deployments. These gaps were filled using a climatology of salinity as a function of temperature and depth that was constructed from post-2010 Loop Current deployments.

Example measurements across the Loop Current and Gulf Stream are shown in Fig. 2. In both cases, the gliders crossed the current from west to east, with measured vertically averaged currents to the left of the gliders' trajectories (Figs. 2a,b). The downstream advection as the gliders crossed the currents is apparent, as is the change in the gliders' trajectories as the speed and direction of the currents changed. Transects of potential temperature (Figs. 2c,d), salinity (Figs. $2 \mathrm{e}, \mathrm{f})$, and absolute downstream geostrophic velocity (Figs. 2g,h) are presented as functions of cross-stream distance; the local streamwise coordinate system is defined in section $2 \mathrm{~b}$. Typical spacing between profiles is less than $5 \mathrm{~km}$ in the cross-stream direction. We estimate absolute downstream geostrophic velocity by calculating geostrophic shear from cross-stream density gradients and referencing those shears to measured vertically averaged currents; an objective mapping routine with a $30-\mathrm{km}$ Gaussian length scale is used to estimate absolute geostrophic velocity (Todd et al. 2011). 

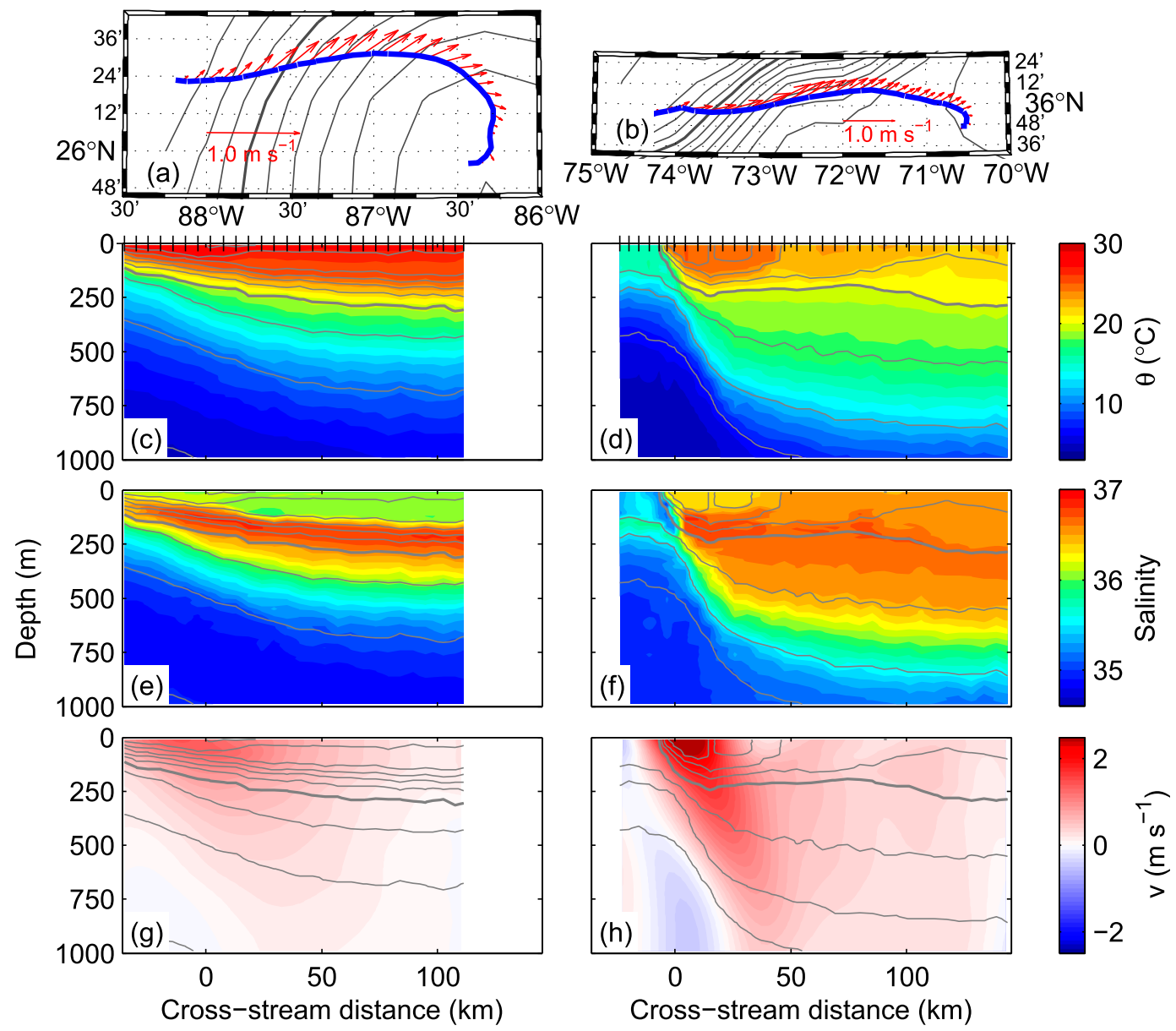

FIG. 2. Example transects across the Loop Current from 27 May to 3 June 2009 (left) and Gulf Stream from 22 December 2008 to 1 January 2009 (right). (a),(b) Horizontal currents averaged over the upper $1000 \mathrm{~m}$ (red) along the glider's tracks (blue) with AVISO mapped absolute dynamic topography for the corresponding time period contoured as in Fig. 1. (c),(d) Potential temperature. (e),(f) Salinity. (g),(h) Absolute downstream geostrophic velocity. Gray contours in (c)-(h) show potential density every $0.5 \mathrm{~kg} \mathrm{~m}^{-3}$ with the $26 \mathrm{~kg} \mathrm{~m}^{-3}$ contour thick. Tick marks on the upper axes of (c) and (d) denote the locations of individual profiles.

We also consider properties along isopycnal surfaces (e.g., Fig. 3). Quantities on isopycnal surfaces are obtained by linear interpolation of the binned $10-\mathrm{m}$ resolution profiles or mapped properties. This representation explicitly filters out horizontal variability due to vertical displacement by internal waves (Rudnick and Cole 2011) and highlights cross-stream changes in water mass properties.

\section{b. Local streamwise coordinate system}

Our analysis is conducted in a local streamwise coordinate system in which the measured vertically averaged current defines the downstream direction $y$ during a given glider dive (Fig. 4). We assume that the flow direction indicated by the vertically averaged current is the flow direction at all sampled depths; we neglect any components of the flow that are perpendicular to the vertically averaged velocity. The downstream direction is oriented at an angle $\phi$ counterclockwise from east. The displacement of a glider during a dive is decomposed into a cross-stream $(\Delta x)$ and an along-stream component $(\Delta y)$. Occasional pairs of profiles are separated by less than $2 \mathrm{~km}$ in the cross-stream direction because of gliders unintentionally heading nearly parallel to the flow; these adjacent profiles are averaged together. As is apparent in Figs. 2a and 2b, the direction of the current may change along a transect. We estimate the local radius of curvature of the flow $R$ as $R=\delta y / \delta \phi$, where $\delta y$ is the alongstream separation between successive dives and the change in orientation between successive dives $\delta \phi$ is measured in radians. Counterclockwise curvature (cyclonic in the Northern Hemisphere) is indicated by 

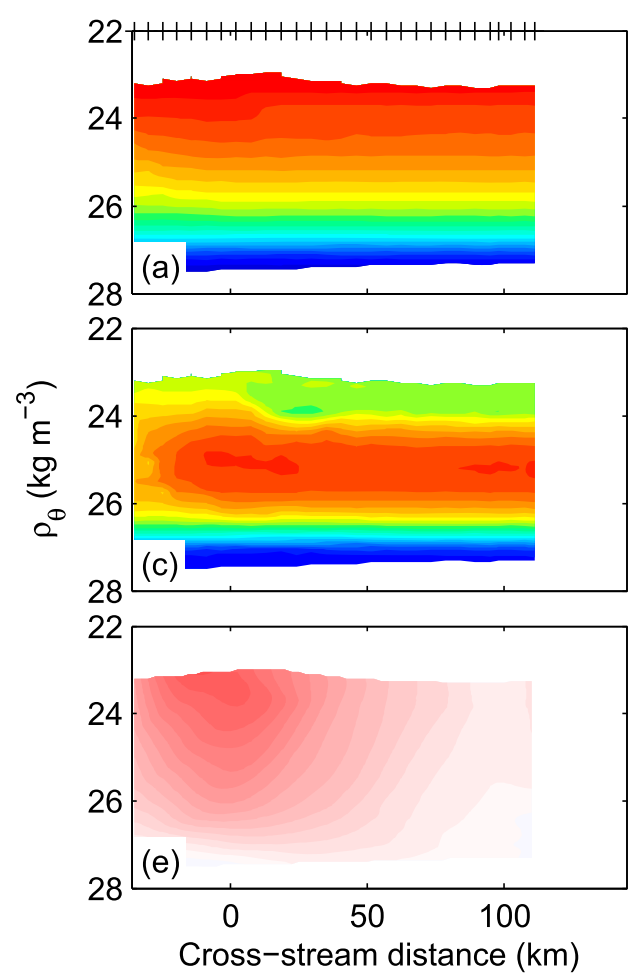
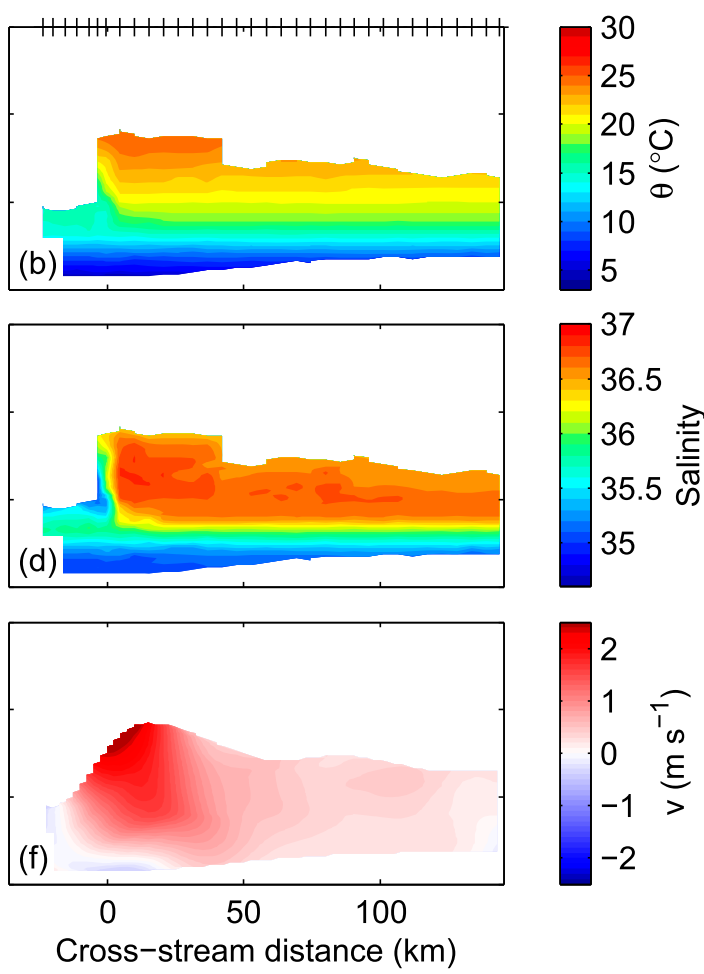

FIG. 3. (a),(b) Potential temperature; (c),(d) salinity; and (e),(f) absolute downstream velocity from the example transects of Fig. 2 shown with potential density as the vertical coordinate. Tick marks on the upper axes of (a) and (b) denote profile locations.

positive values of $R$. Inverse radii of curvature nearly always have magnitudes less than $3 \times 10^{-5} \mathrm{~m}^{-1}$, with more than $70 \%$ of estimates having magnitudes less than $1 \times 10^{-5} \mathrm{~m}^{-1}$ (Fig. 5a); radii of curvature are typically greater than $100 \mathrm{~km}$ in the Loop Current and Gulf Stream. Summation of cross-stream displacements during a transect gives a measure of cross-stream distance as the horizontal coordinate (e.g., Fig. 2). In the Gulf Stream, the origin of the cross-stream distance is chosen as the location where the $15^{\circ} \mathrm{C}$ isotherm is found at a depth of $200 \mathrm{~m}$ (Fuglister and Voorhis 1965). In the Loop Current, the location at which the glider's path crosses the 40-cm SSH contour in the weekly AVISO mapped absolute dynamic topography product is used as the origin since gradients of hydrographic properties are weaker than in the Gulf Stream (e.g., Fig. 2). In the long-term mean, the 40-cm SSH contour runs continuously from the Yucatan Channel to beyond Cape Hatteras (Fig. 1) and may be thought of as a representative streamline connecting two segments of the western boundary current.

\section{c. Potential vorticity in streamwise coordinates}

We calculate potential vorticity [Eq. (1)] in the streamwise coordinate system defined above (Fig. 4). The vector representing the earth's rotation at latitude $\lambda$ with rotational rate $\Omega$ is $2 \boldsymbol{\Omega}=[0,2 \Omega \cos \lambda, 2 \Omega \sin \lambda]$ in an unrotated coordinate system [Salmon 1998, his Eq. (1.17)]. Letting $f=2 \Omega \sin \lambda$ and rewriting in our local streamwise coordinate system (Fig. 4), we have $2 \boldsymbol{\Omega}=[-f \cot \lambda \cos \phi$, $f \cot \lambda \sin \phi, f]$. In a local streamwise coordinate system in which $R$ varies with each local application and flow normal to the measured vertically averaged current is neglected, the expression for the relative vorticity is $\zeta=[-\partial v / \partial z, 0, \partial v / \partial x+v / R]$, where $v$ is downstream velocity (Fig. 4) and $v / R$ is the contribution of flow curvature (Holton 1979; Bower 1989). For our observations, the flow curvature contribution to the relative vorticity is less than half the size of the cross-stream gradient contribution more than $70 \%$ of the time and has a larger magnitude than the cross-stream gradient not more than $10 \%$ of the time (Fig. 5b). Without constructing a streamwise coordinate system and assuming that cross-stream velocities are negligible, our estimate of relative vorticity would be limited to the along-track derivative of cross-track velocity (the "one ship" method; Rudnick 2001; Shcherbina et al. 2013), which would strongly underestimate relative vorticity when a glider crosses the western boundary current obliquely.

Substituting the expressions for $2 \boldsymbol{\Omega}$ and $\boldsymbol{\zeta}$ into Eq. (1) and expressing the squared buoyancy frequency as 


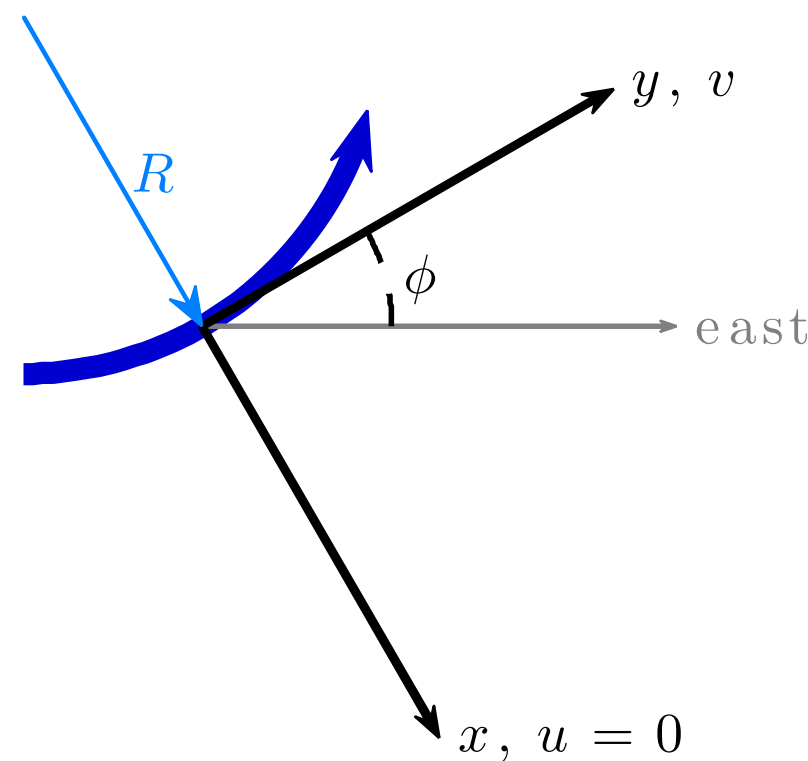

FIG. 4. Local streamwise coordinate system used for analysis of glider transects. The downstream $(y)$ direction at each profile location is defined by the measured vertically averaged current (dark blue) and is oriented at an angle $\phi$ counterclockwise from east. The radius of curvature of the flow ( $R$, light blue) is estimated from the dive-to-dive change in orientation of the flow.

$N^{2}=-(g / \rho)\left(\partial \rho_{\theta} / \partial z\right)$ gives the potential vorticity in streamwise coordinates as

$$
\begin{aligned}
Q= & \frac{N^{2}}{g} f+\frac{N^{2}}{g}\left(\frac{\partial v}{\partial x}+\frac{v}{R}\right)+\frac{1}{\rho} \frac{\partial v}{\partial z} \frac{\partial \rho_{\theta}}{\partial x} \\
& +\frac{f}{g} \cot \lambda \cos \phi\left(\frac{g}{\rho} \frac{\partial \rho_{\theta}}{\partial x}\right) .
\end{aligned}
$$

We assume that the flow is in geostrophic balance and use the thermal wind relation to write the vertical shear as $\partial v / \partial z=-\left.[g /(\rho f)](\partial \rho / \partial x)\right|_{p}=-[g /(\rho f)]\left(\partial \rho_{\theta} / \partial x\right)$. Substituting into Eq. (2), we arrive at the following expression for the potential vorticity:

$$
\begin{aligned}
Q= & \frac{N^{2}}{g} f+\frac{N^{2}}{g}\left(\frac{\partial v}{\partial x}+\frac{v}{R}\right)-\frac{1}{f g}\left(\frac{g}{\rho} \frac{\partial \rho_{\theta}}{\partial x}\right)^{2} \\
& +\frac{f}{g} \cot \lambda \cos \phi\left(\frac{g}{\rho} \frac{\partial \rho_{\theta}}{\partial x}\right) .
\end{aligned}
$$

By assuming a thermal wind balance, we have neglected the potential impacts of centripetal acceleration $\left(v^{2} / R\right)$ in a curving flow under a gradient wind balance. Following Holton (1979), the thermal wind must be scaled by a factor of $\{1+[v /(\mathrm{fR})]\}^{-1}$ to obtain the gradient wind; for typical velocities of $1 \mathrm{~m} \mathrm{~s}^{-1}$, typical radii of curvature for the Loop Current and Gulf Stream of $100 \mathrm{~km}$, and values of $f$ ranging from $5.5 \times 10^{-5}$ to $9.5 \times$ $10^{-5} \mathrm{~s}^{-1}$ for the latitudes of interest, this scaling would typically result in a $10 \%-20 \%$ change in magnitude of the baroclinic flow. Additionally, as noted by Rudnick et al. (2015), the vertically averaged currents used to reference geostrophic shear are directly measured and include any cyclostrophic effects.

The right-hand sides of Eqs. (2) and (3) split the potential vorticity into the contributions from the vertical component of the planetary vorticity (first term), the vertical component of the relative vorticity (second term), the horizontal component of the relative vorticity (third term), and the horizontal component of the planetary vorticity (fourth term). It should be noted that, to the extent that the flow is in thermal wind balance, the horizontal component of the relative vorticity is always of the opposite sign of the planetary vorticity [Eq. (3)], so that baroclinicity in the flow always causes the flow to tend toward instability (Thomas et al. 2013). Scaling with values typical for the western boundary current suggests that the horizontal component of the planetary vorticity (fourth term) should be negligibly small; we verify this below with example observations.

Each term in Eq. (3) can be evaluated using glider observations of potential density and estimates of flow curvature and velocity, so we are able to obtain crossstream potential vorticity distributions for each transect across the Gulf Stream and Loop Current. To do so, we use an objective mapping routine with a 30-km Gaussian length scale to map $N^{2}, R^{-1}, \rho, \partial \rho_{\theta} / \partial x$, and $\phi$ to a regularly spaced cross-stream grid for each transect. Inverse radius of curvature, $R^{-1}=\delta \phi / \delta y$, is mapped rather than radius of curvature to obtain a smoother field. Mapped fields are then used to evaluate Eq. (3) for each crossstream transect.

\section{Results and discussion}

\section{a. Example transects}

Representative transects of hydrography and velocity across the Loop Current and Gulf Stream (Figs. 2, 3) highlight the contrast between these two segments of the western boundary current. Property gradients are much stronger across the Gulf Stream; the strong cross-frontal density gradients in the Gulf Stream support more intense downstream flow compared to the Loop Current (Figs. 2g,h). Downstream volume transports above $1000 \mathrm{~m}$ through these transects are 39 Sverdrups $\left(\mathrm{Sv} ; 1 \mathrm{~Sv} \equiv 10^{6} \mathrm{~m}^{3} \mathrm{~s}^{-1}\right)$ in the Loop Current and $72 \mathrm{~Sv}$ in the Gulf Stream, demonstrating the expected increase in transport between the Gulf of Mexico and Cape Hatteras.

The potential vorticity from the example transect across the Gulf Stream (Fig. 6, right column) shows 

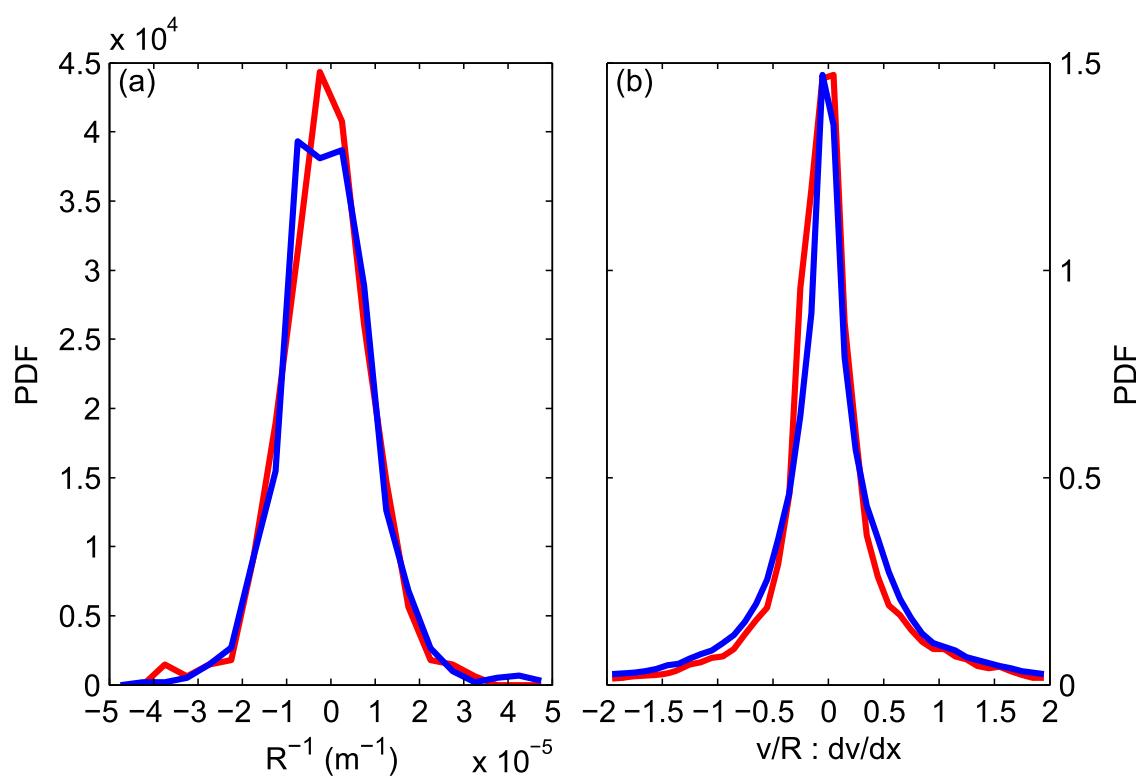

FIG. 5. Probability density functions of (a) objectively mapped inverse radius of curvature $\left(R^{-1}\right)$ and (b) the ratio of $v / R$ to $\partial v / \partial x$ for the Loop Current (blue) and Gulf Stream (red).

well-known features such as low subsurface potential vorticity on the offshore side of the Gulf Stream due to low stratification in the Eighteen Degree Water (Fig. 6b; e.g., McCartney 1982); more intense cyclonic shear than anticyclonic shear (Fig. 6f; e.g., Johns et al. 1995), particularly below the thermocline; strong potential vorticity gradients along shallow isopycnals and weak gradients on deeper isopycnals (Fig. 7b; e.g., Bower et al. 1985); and low total potential vorticity in the upper $100 \mathrm{~m}$ on both the seaward (Thomas and Joyce 2010) and shoreward (cf. Thomas et al. 2013, their Fig. 3) sides of the Gulf Stream (Fig. 6b). The example potential vorticity transect across the Loop Current (Fig. 6, left column) lacks many of these features, further demonstrating the changes in structure of the western boundary current between the Gulf of Mexico and downstream of Cape Hatteras. As expected, the horizontal component of the planetary vorticity does not contribute significantly to the total potential vorticity (Fig. 6i-j).

\section{b. Mean transects}

To highlight persistent features in the cross-stream hydrographic and potential vorticity structure, we construct mean cross-stream distributions of various properties by averaging transects in our cross-stream coordinate system. Such averages reduce effects of high-frequency processes that are aliased into the horizontal structure because of the relatively slow speed of the gliders (Rudnick and Cole 2011). Mean fields are constructed from regularly spaced fields for individual transects that are produced by objective mapping with a 30-km Gaussian length scale, which also helps to reduce the effects of internal waves. We then average these mapped transects together to produce mean transects for the Loop Current and Gulf Stream. Mean transects are constructed using both depth and density as vertical coordinates. For both segments of the western boundary current, mean transects are only shown for cross-stream positions occupied at least six times by gliders; consequently, our analysis is restricted to a $160-\mathrm{km}$-wide portion of both the Loop Current and the Gulf Stream. The appendix discusses errors associated with these mean transects, which we attribute primarily to temporal and alongstream variability within each segment of the western boundary current.

\section{1) TEMPERATURE, SALINITY, AND DOWNSTREAM VELOCITY}

Mean cross-stream distributions of temperature, salinity, and downstream velocity for the Gulf Stream (Figs. 8 and 9, right column) show structures that agree well with prior work using different observing methods. Mean cross-frontal temperature gradients in the Gulf Stream (Fig. 8b) agree well with the stream coordinate averages of Halkin and Rossby (1985, their Fig. 10) using bimonthly observations from free-falling Pegasus profilers during September 1980 to May 1983 near $73^{\circ} \mathrm{W}$. Mean cross-stream salinity structure (Fig. 8d) shows the same subsurface salinity maximum seaward of the core of the Gulf Stream that is found in the 2004-08 mean 

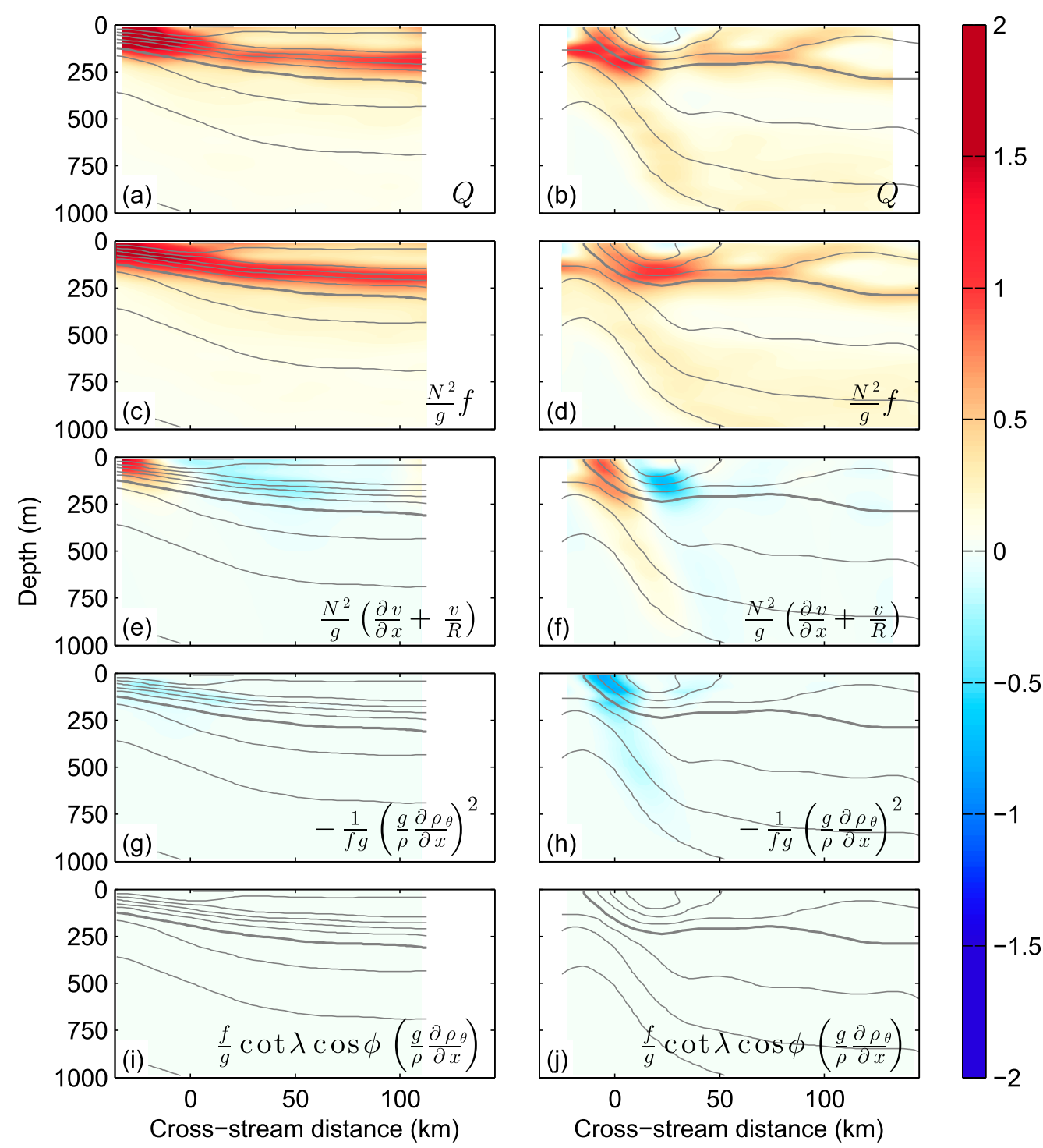

(h)
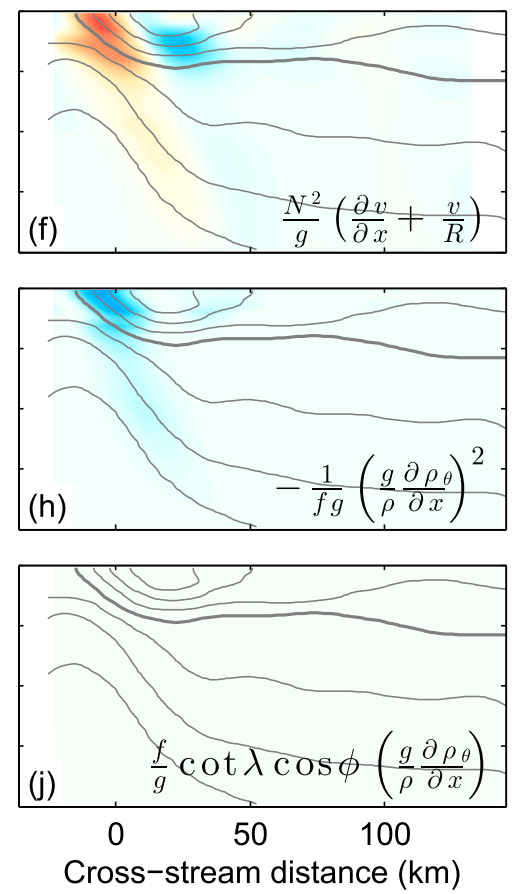

FIG. 6. Potential vorticity across the (left) Loop Current and (right) Gulf Stream from the example transects shown in Figs. 2 and 3. (a),(b) Total potential vorticity and contributions from (c),(d) the vertical component of the planetary vorticity; (e),(f) the vertical component of the relative vorticity; (g),(h) the horizontal component of the relative vorticity; and (i),(j) the horizontal component of the planetary vorticity are shown on the same color scale. Contours of mapped potential density are shown every $0.5 \mathrm{~kg} \mathrm{~m}^{-3}$ with the $26.0 \mathrm{~kg} \mathrm{~m}^{-3}$ isopycnal thicker.

from ship-based measurements along Line W, a mooring and repeat hydrographic line between the outer shelf south of Cape Cod and Bermuda (Toole et al. 2011). Qu et al. (2013) used a simulated passive tracer and its adjoint to show that this salinity maximum water forms at the surface in the northwestern subtropical gyre, then subducts as it circulates around the gyre. The largest cross-stream property gradients occurred along isopycnals that were observed to outcrop locally at least once during the observational period (the densest such isopycnal at a given cross-stream position is indicated by the dashed line in Fig. 9). Mean downstream velocities from the glider observations show similar magnitudes and structure to the stream coordinate averages of Halkin and Rossby (1985, their Fig. 10) as well as those of Johns et al. (1995) near $68^{\circ} \mathrm{W}$ using the Synoptic Ocean Prediction experiment (SYNOP) array of current meters from June 1988 to August 1990 and of Rossby and Zhang (2001) using shipboard ADCP data along the Motor Vessel (M/V) Oleander line between Elizabeth, New Jersey, and Hamilton, Bermuda. In each of these estimates of velocity structure in the detached Gulf Stream, maximum downstream speed approaches $2 \mathrm{~m} \mathrm{~s}^{-1}$ near the surface and decays to approximately $0.3 \mathrm{~m} \mathrm{~s}^{-1}$ at 

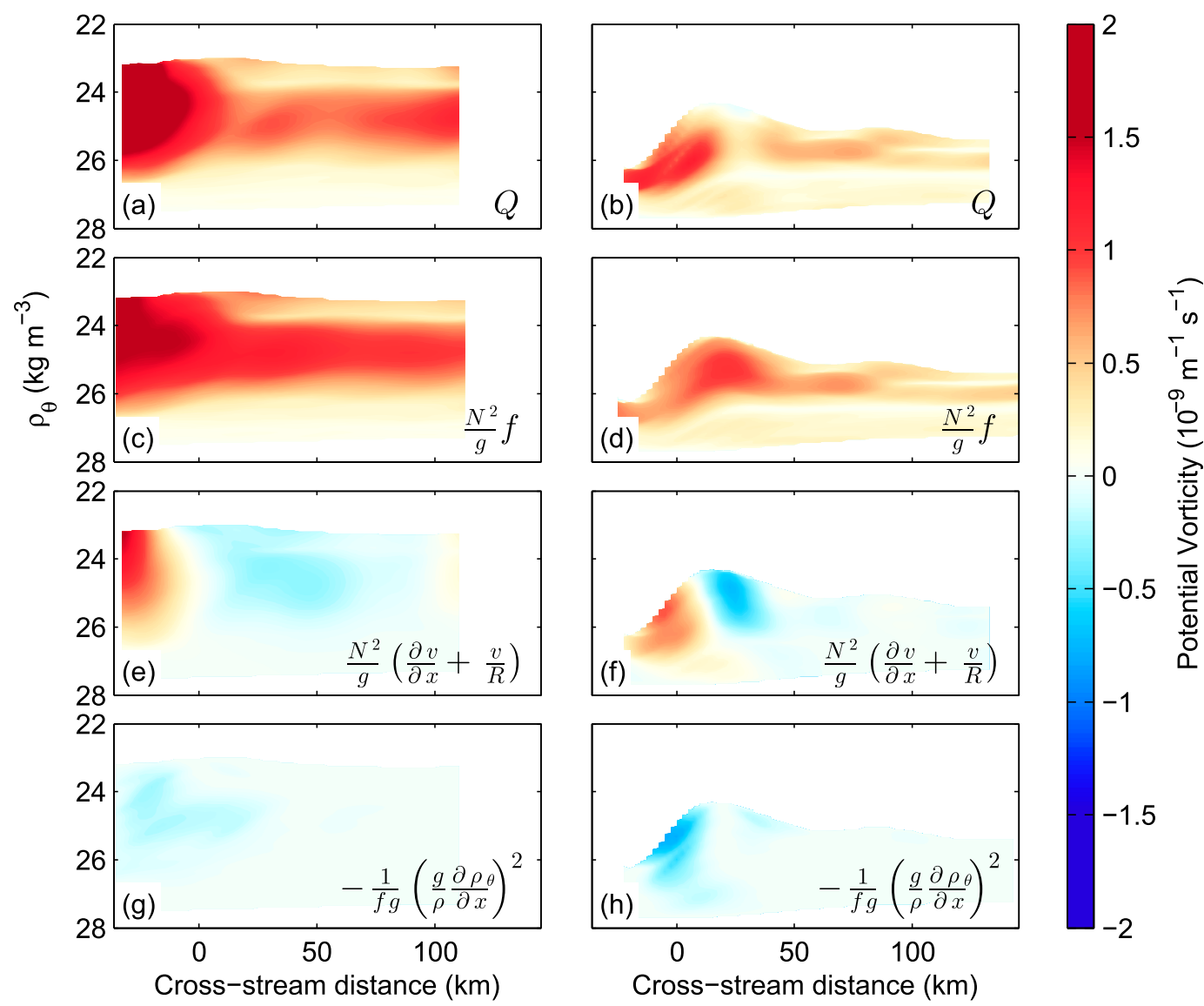

FIG. 7. (a),(b) Total potential vorticity and contributions from (c),(d) the vertical component of the planetary vorticity; (e),(f) the vertical component of the relative vorticity; and (g),(h) the horizontal component of the relative vorticity from the example transects of Figs. 2 and 3 with potential density as the vertical coordinate.

$1000 \mathrm{~m}$, with the location of maximum velocity shifting offshore by about $40 \mathrm{~km}$ from the surface to $1000 \mathrm{~m}$ (Fig. 8f). Downstream transport calculated from the averaged velocity field is $78 \mathrm{~Sv}$; the mean and standard deviation of downstream transport calculated from individual transects is $75 \pm 12 \mathrm{~Sv}$. For comparison, Johns et al. (1995) reported a volume transport of $79.7 \mathrm{~Sv}$ in the upper $1000 \mathrm{~m}$ at $68^{\circ} \mathrm{W}$. The agreement between mean crossstream distributions constructed from the glider observations and from other, longer observational datasets engenders confidence that the 11 cross-Gulf Stream glider transects analyzed here provide an adequate representation of the Gulf Stream's mean structure.

In the Loop Current, the dense observations provided by the gliders allow construction of mean cross-stream transects (Fig. 8, left column) in a segment of the western boundary current that has been less well observed in the past. As noted in the comparison of example transects (Fig. 2), cross-frontal gradients of temperature, salinity, and density are much weaker in the Loop Current than in the Gulf Stream. These weaker cross-frontal gradients support downstream flow that is notably weaker than in the Gulf Stream. With maximum surface temperatures exceeding $28^{\circ} \mathrm{C}$ and the $20^{\circ} \mathrm{C}$ isotherm varying from 100 to $240 \mathrm{~m}$ depth across the current, the mean temperature structure of the Loop Current in the Gulf of Mexico (Fig. 8a) compares well with the mean temperature distribution across the $\mathrm{Yu}$ catan Channel in Candela et al. (2002). This suggests that the cross-stream structure of the current does not change significantly within the Gulf of Mexico. Both year-round and seasonal stratification are stronger in the Loop Current than in the Gulf Stream, as evidenced by the wider density range below and above the densest outcropping isopycnal in the Loop Current (Fig. 9). Differences in water mass properties (i.e., alongisopycnal temperature and salinity gradients) across the Loop Current above $26.5 \mathrm{~kg} \mathrm{~m}^{-3}$ (Figs. 9a,c) are much less pronounced than across the Gulf Stream (Figs. 9b,d). Downstream transport calculated from the averaged velocity field for the Loop Current is $47 \mathrm{~Sv}$; the mean and standard deviation of downstream transport 

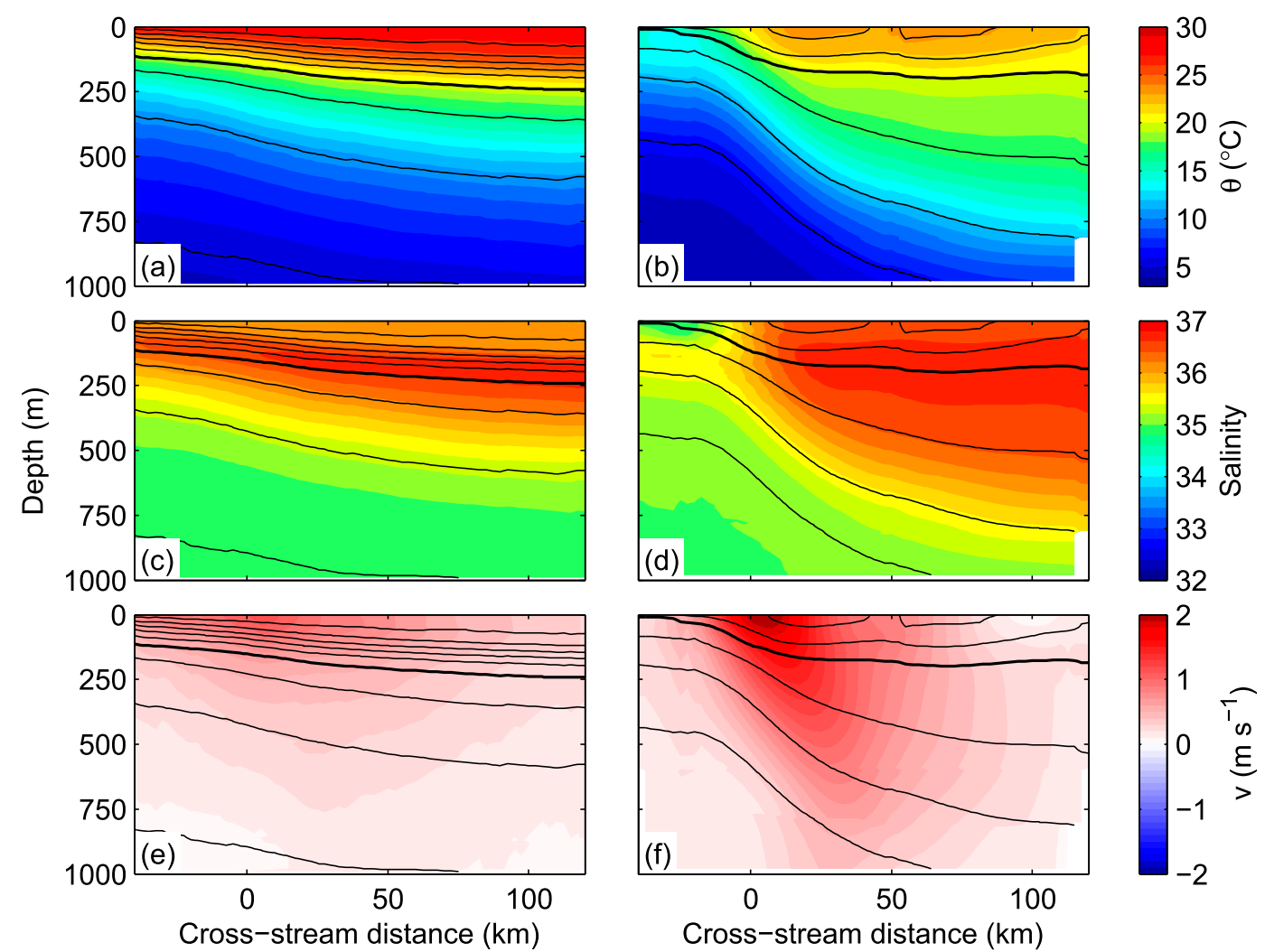

FIG. 8. Mean properties in the (left) Loop Current and (right) Gulf Stream. Colors show (a),(b) potential temperature; (c),(d) salinity; and (e),(f) absolute downstream geostrophic velocity. Black contours of mean potential density are as in Fig. 2. Mean values are only shown at positions covered by at least six glider transects.

calculated from individual transects is $41 \pm 15 \mathrm{~Sv}$. Though the cross-stream shape of the Loop Current in the Gulf of Mexico (Fig. 8e) is similar to that in the Yucatan Channel (Candela et al. 2002), downstream transports in the Loop Current are notably greater than both the $24 \mathrm{~Sv}$ estimate of net volume transport through the Yucatan Channel (Sheinbaum et al. 2002) and the 30-34 Sv transport estimate through the Florida Straits (e.g., Baringer and Larsen 2001). The discrepancy between our Loop Current transport estimate and the Yucatan Channel and Florida Straits estimates is likely due to recirculation within Gulf of Mexico and the additive effect of small cyclonic eddies along the edge of the Loop Current (e.g., Rudnick et al. 2015), which may be partially included in identified Loop Current transects.

To highlight the alongstream changes in western boundary current structure between the Gulf of Mexico and the western North Atlantic, Fig. 10 shows the difference between the mean Gulf Stream potential temperature, salinity, potential density, and absolute geostrophic velocity and the corresponding Loop Current means from Fig. 8. In the upper $150-200 \mathrm{~m}$ of the water column, alongstream cooling, presumably through surface heat loss, and an increase in salinity on the seaward side of the current result in upper-layer densities that are as much as $2 \mathrm{~kg} \mathrm{~m}^{-3}$ greater in the Gulf Stream. Below $200 \mathrm{~m}$, cross-frontal gradients of temperature, salinity, and density all increase downstream. Waters on the (warm, salty, and light) seaward side of the front become warmer, saltier, and lighter downstream while waters on the (cool, fresh, dense) shoreward side of the front become cooler, fresher, and denser, largely because of the influence of slope sea waters (Csanady and Hamilton 1988). The salinity trend acts to compensate some of the temperature effect on density, but temperature remains the dominant property influencing changes in cross-stream density gradients. This downstream increase in cross-frontal density gradients is consistent with the intensification of alongstream velocities between the Loop Current and the Gulf Stream (Fig. 10d).

\section{2) Potential vorticity}

We now consider the mean cross-stream potential vorticity structure in the Loop Current and Gulf Stream. Mean potential vorticity $Q$ is at least marginally positive everywhere in both portions of the western boundary 

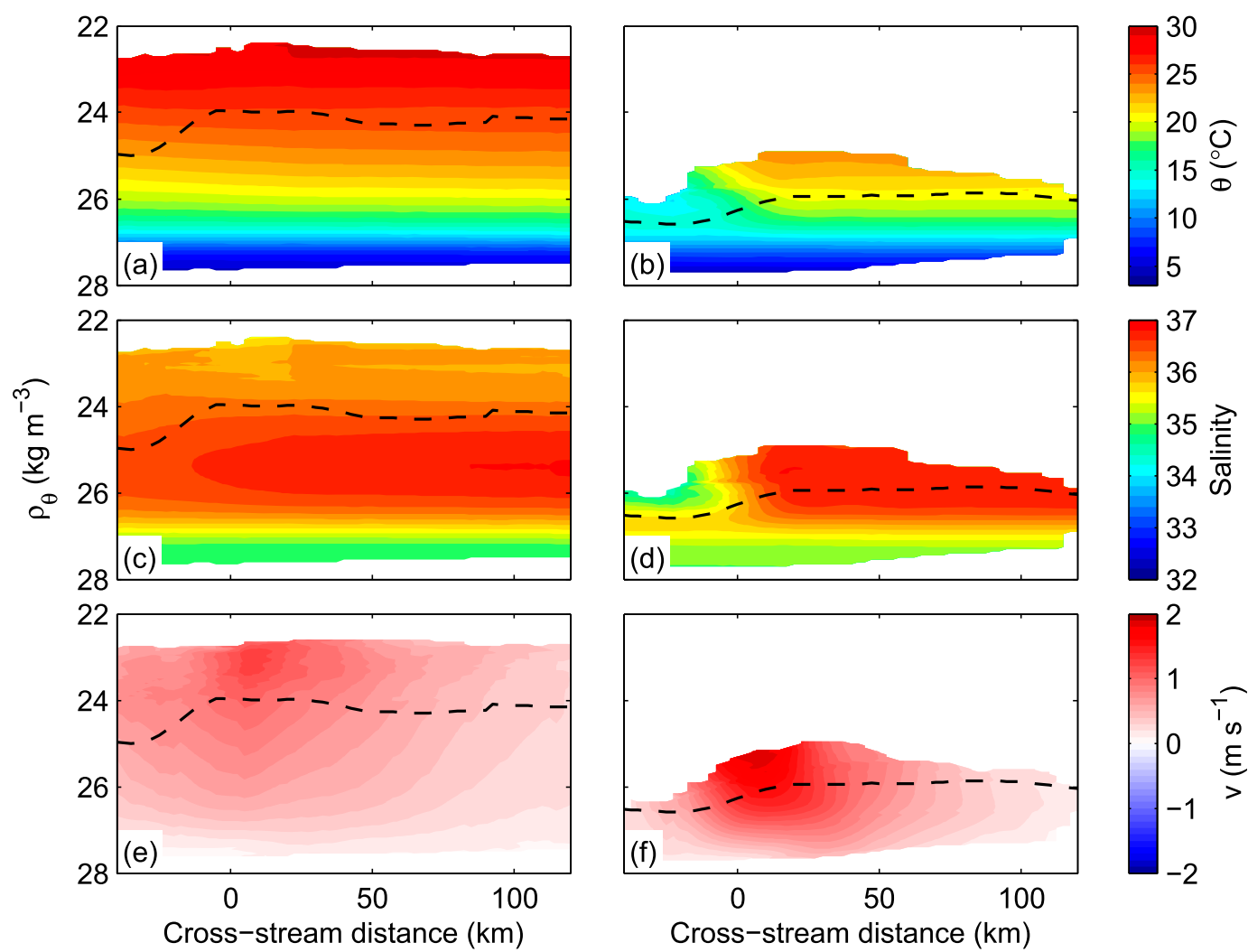

FIG. 9. Mean properties in the (left) Loop Current and (right) Gulf Stream as functions of potential density and cross-stream position. Colors show (a),(b) potential temperature; (c),(d) salinity; and (e),(f) absolute downstream geostrophic velocity. The dashed lines indicate the densest outcropping isopycnal observed at each cross-stream position.

current (Figs. 11a,b); this is to be expected since the instabilities that result when potential vorticity takes the opposite sign of the Coriolis parameter will quickly restore the potential vorticity to positive values in the Northern Hemisphere. Potential vorticity is most strongly positive in the upper $100 \mathrm{~m}$ of the water column on the shoreward half of the current where strong stratification (Figs. 11c,d) and cyclonic relative vorticity (Figs. 11e,f) are found. Maximum total potential vorticity is about $2.7 \times 10^{-9} \mathrm{~m}^{-1} \mathrm{~s}^{-1}$ in the Loop Current and about $3.7 \times 10^{-9} \mathrm{~m}^{-1} \mathrm{~s}^{-1}$ in the Gulf Stream. In the Loop Current, mean near-surface potential vorticity remains above $0.25 \times 10^{-9} \mathrm{~m}^{-1} \mathrm{~s}^{-1}$ on the seaward side of the current (Fig. 11a) because of the strong stratification (Fig. 11c) and weak anticyclonic relative vorticity (Fig. 11e). In the Gulf Stream, on the other hand, mean near-surface potential vorticity drops as low as $0.06 \times$ $10^{-9} \mathrm{~m}^{-1} \mathrm{~s}^{-1}$ (Fig. 11b), where somewhat weaker stratification (Fig. 11d) is nearly canceled out by strong anticyclonic relative vorticity (Fig. 11f). Below the maximum in potential vorticity along the thermocline, total potential vorticity decays monotonically with depth in the Loop Current and on the shoreward side of the Gulf Stream, but there is a secondary maximum along the $27 \mathrm{~kg} \mathrm{~m}^{-3}$ isopycnal on the seaward side of the Gulf Stream that results from increased stratification below the weakly stratified mode waters in which mean potential vorticity is less than $0.07 \times 10^{-9} \mathrm{~m}^{-1} \mathrm{~s}^{-1}$. The horizontal component of the relative vorticity (Figs. 11g,h) is the largest negative contributor to the mean potential vorticity in both the Loop Current and Gulf Stream with minimum values of $-0.26 \times 10^{-9}$ and $-0.42 \times 10^{-9} \mathrm{~m}^{-1} \mathrm{~s}^{-1}$, respectively, but its collocation with the cyclonic side of the stream limits its influence on total potential vorticity.

Figure 12 shows the mean potential vorticity and contributions from terms in Eq. (3) as functions of density and cross-stream position. Along-isopycnal potential vorticity gradients are apparent in the upper water column in both the Loop Current and the Gulf Stream and may serve as barriers to cross-frontal exchange as suggested by Bower et al. (1985), while potential vorticity is uniform along isopycnals in the lower portion of the water column. The low-potential-vorticity signature of mode waters on the seaward side of the Gulf Stream is confined to a narrow range of isopycnals centered at a potential density of $26.35 \mathrm{~kg} \mathrm{~m}^{-3}$. 


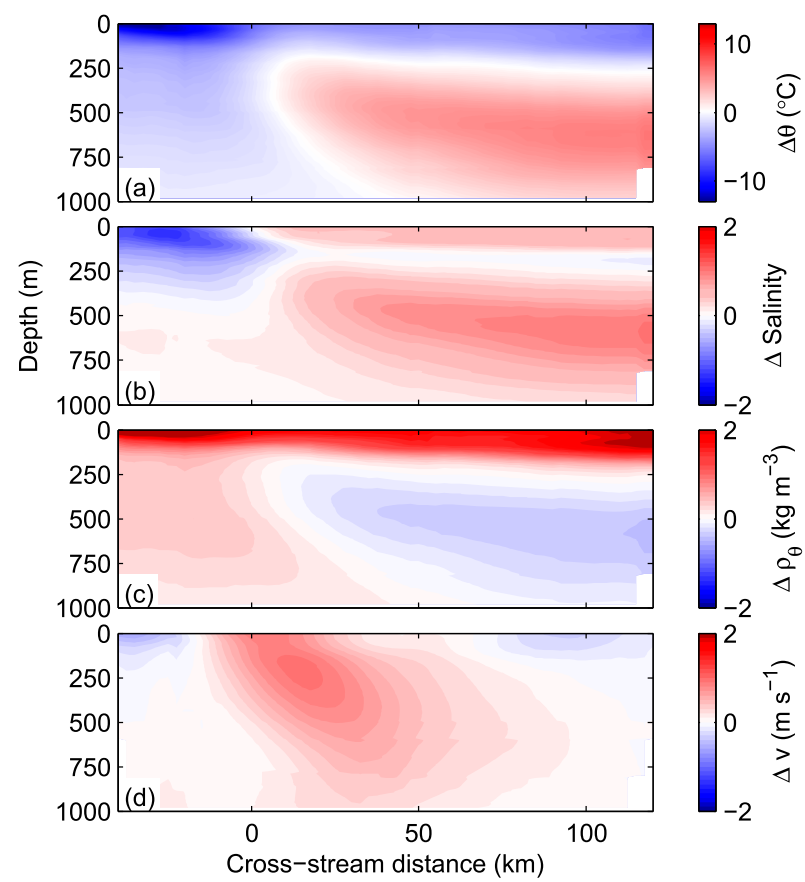

FIG. 10. Changes in mean (a) potential temperature, (b) salinity, (c) potential density, and (d) downstream velocity between the Loop Current and Gulf Stream.

Downstream changes in mean potential vorticity structure between the Loop Current and the detached Gulf Stream are highlighted in Fig. 13, which shows the difference between mean potential vorticity in the Gulf Stream and that in the Loop Current (Figs. 11, 12). Downstream changes in the vertical component of the planetary vorticity (i.e., changes in stratification and the downstream increase in $f$; Figs. $13 \mathrm{c}, \mathrm{d})$ contribute most of the change in potential vorticity structure as the western boundary current flows northward. The increase in relative vorticity in the Gulf Stream (Figs. 13e,f) amplifies the effects of planetary vorticity except within a $20-\mathrm{km}$-wide region on the cyclonic side of the Gulf Stream above $100 \mathrm{~m}$, where the increase in positive relative vorticity overwhelms the loss of potential vorticity because of reduced stratification. Increased baroclinicity in the Gulf Stream (i.e., steeper isopycnals) tends to moderate changes in potential vorticity caused by the vertical component of the relative vorticity (Figs. 13g,h). Cross-stream, along-isopycnal gradients of potential vorticity increase above the $26.75 \mathrm{~kg} \mathrm{~m}^{-3}$ isopycnal (Fig. 13b) because of the combined effects of the vertical planetary vorticity and vertical relative vorticity, likely making the Gulf Stream a more efficient barrier to cross-frontal exchange at these levels (e.g., Bower et al. 1985); below $26.75 \mathrm{~kg} \mathrm{~m}^{-3}$, total potential vorticity increases uniformly along each isopycnal between the Loop Current and Gulf Stream.

\section{c. Instability criteria}

Here we evaluate various instability criteria using the glider-derived potential vorticity structure in the North Atlantic western boundary current. In a quasigeostrophic framework, cross-stream changes in sign of the mean potential vorticity gradient are a necessary (though not sufficient) condition for barotropic instability (Holton 1979; Gill 1982) while vertical changes in sign are a necessary condition for baroclinic instability. Key assumptions of quasigeostrophic theory (i.e., low Rossby numbers and small changes in upper-layer thickness) are violated in the western boundary current (Johns 1988), but the theory has nonetheless proven useful in understanding the behavior of strong oceanic currents (e.g., Wright 1981; Johns 1988) and we will apply the theory here without further justification. Areas of negative potential vorticity are inherently unstable, and, consistent with this, mean potential vorticity is everywhere positive (Figs. 11a,b), but areas of $Q<0$ may be found in snapshots. When the absolute vorticity, $\zeta_{\text {abs }}=f+\zeta$, is negative, the flow experiences centrifugal instability; here, $\zeta=(\partial v / \partial x)+(v / R)$ is the vertical component of the relative vorticity vector $\zeta$. When $N^{2} \zeta$ abs is positive but smaller in magnitude than the (negative definite) horizontal relative vorticity term, $-(1 / f g)\left[(g / \rho)\left(\partial \rho_{\theta} / \partial x\right)\right]^{2}$, the flow experiences symmetric instability (Thomas et al. 2013).

\section{1) MEAn POTENTIAL VORTICITY GRADIENT}

Figure 14 shows the cross-stream gradients of the mean potential vorticity for the Loop Current and Gulf Stream, which are constructed by first differencing the mean potential vorticity fields shown in Figs. 11a and 11b. Crossstream changes in the sign of $d Q / d x$ are apparent in both the Loop Current and Gulf Stream, suggesting both portions of the western boundary current meet the condition for barotropic instability. In the Loop Current, these sign changes are primarily in the upper $150 \mathrm{~m}$; the mean potential vorticity is nearly uniform in the deeper portions of the Loop Current (Fig. 11a), so potential vorticity gradients are negligible below $150 \mathrm{~m}$. In the Gulf Stream, cross-stream changes of sign of $d Q / d x$ are apparent throughout the upper $1000 \mathrm{~m}$ within the tilted core of the current. Vertical changes in the sign of $d Q / d x$ are also apparent in both the Loop Current and Gulf Stream, such as at depths of 100-200 m and cross-stream positions of between -40 and $70 \mathrm{~km}$ in the Loop Current (Fig. 14a) and within the anticyclonic portion of the Gulf Stream (Fig. 14b). Vertical changes of the sign of the potential vorticity gradient are much more pronounced in the Gulf Stream where potential vorticity gradients are substantially different from zero below $250 \mathrm{~m}$ because of both the deep stratification maximum below the mode 

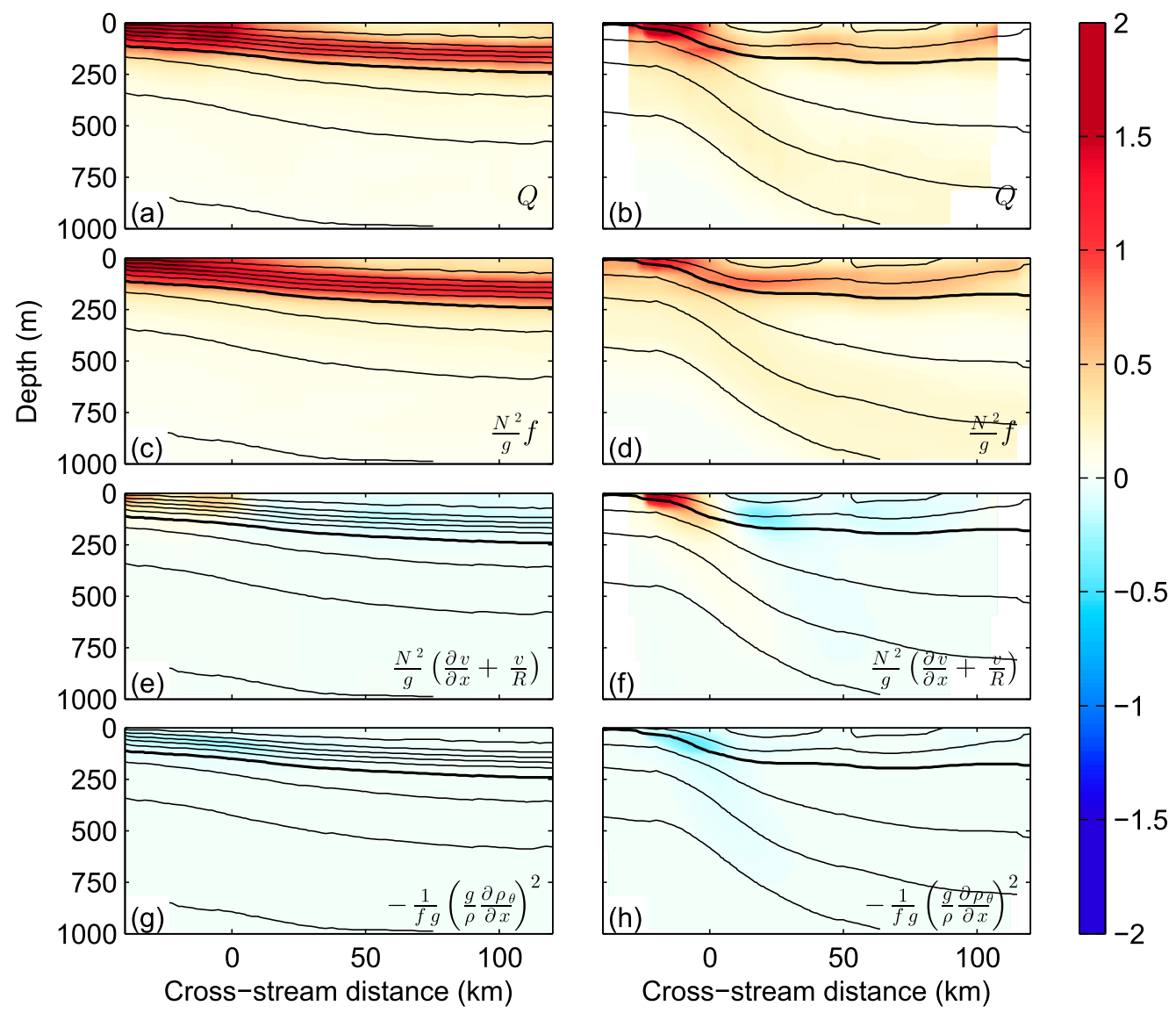

$-1$

Tंs

0.5

ז'

0

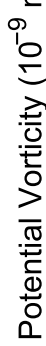

FIG. 11. Mean potential vorticity in the (left) Loop Current and (right) Gulf Stream. (a),(b) Total potential vorticity and contributions from (c),(d) the vertical component of the planetary vorticity; (e),(f) the vertical component of the relative vorticity; and $(\mathrm{g}),(\mathrm{h})$ the horizontal component of the relative vorticity are shown on the same color scale. The contribution from the horizontal component of the planetary vorticity is not shown as it is negligibly small (e.g., Fig. 6i,j). Contours of mean potential density are as in Fig. 8. Mean values are only shown at positions covered by at least six glider transects.

waters (Fig. 11d) and the tilting of the current with depth; this is consistent with the stronger density gradients and greater vertical shear in the Gulf Stream (Figs. 10c,d) that provide a larger pool of available potential energy to fuel baroclinic instabilities.

\section{2) Absolute vorticity}

Figures $15 \mathrm{a}$ and $15 \mathrm{c}$ show the frequency of gliderbased estimates of $\zeta_{\text {abs }}$ that are less than zero in the Loop Current and Gulf Stream, respectively, as functions of depth and cross-stream position. These estimates suggest that the criterion for centrifugal instability is met in both the Loop Current and the Gulf Stream above $150 \mathrm{~m}$ depth (Figs. 15a,c), where the vertical component of the relative vorticity is largest. In the Loop Current, our estimate of $\zeta_{\text {abs }}$ is negative in $28 \%$ of transects (11 out of 40) at various cross-stream positions within $50 \mathrm{~km}$ of the origin of coordinates (i.e., the $40-\mathrm{cm} \mathrm{SSH} \mathrm{contour)} \mathrm{with}$ rates of occurrence of $5 \%-10 \%$ at any particular location. Estimates of $\zeta_{\mathrm{abs}}<0$ are found in $36 \%$ of Gulf Stream transects (4 out of 11) with the occurrences confined to a $30-\mathrm{km}$-wide region on the seaward side of the Gulf Stream core and rates of occurrence approaching $25 \%$ at any particular location. With the exception of one instance in the Loop Current when the curvature vorticity $(v / R)$ was the same size as shear vorticity $(\partial v / \partial x)$, estimates of $\zeta_{\mathrm{abs}}<0$ occur when curvature vorticity is less than half the size (and sometimes has the opposite sign) of $\partial v / \partial x$. The Loop Current is typically broader than the Gulf Stream (e.g., Fig. 2) and exhibits a dual-core structure in some transects (not shown), which likely explains the broader distribution of negative absolute vorticity estimates in the Loop Current. Estimates of $\zeta_{\text {abs }}<0$ are found throughout the year in the Loop Current; the four Gulf Stream transects showing $\zeta_{\text {abs }}<0$ (including the one shown in Figs. 2 and 

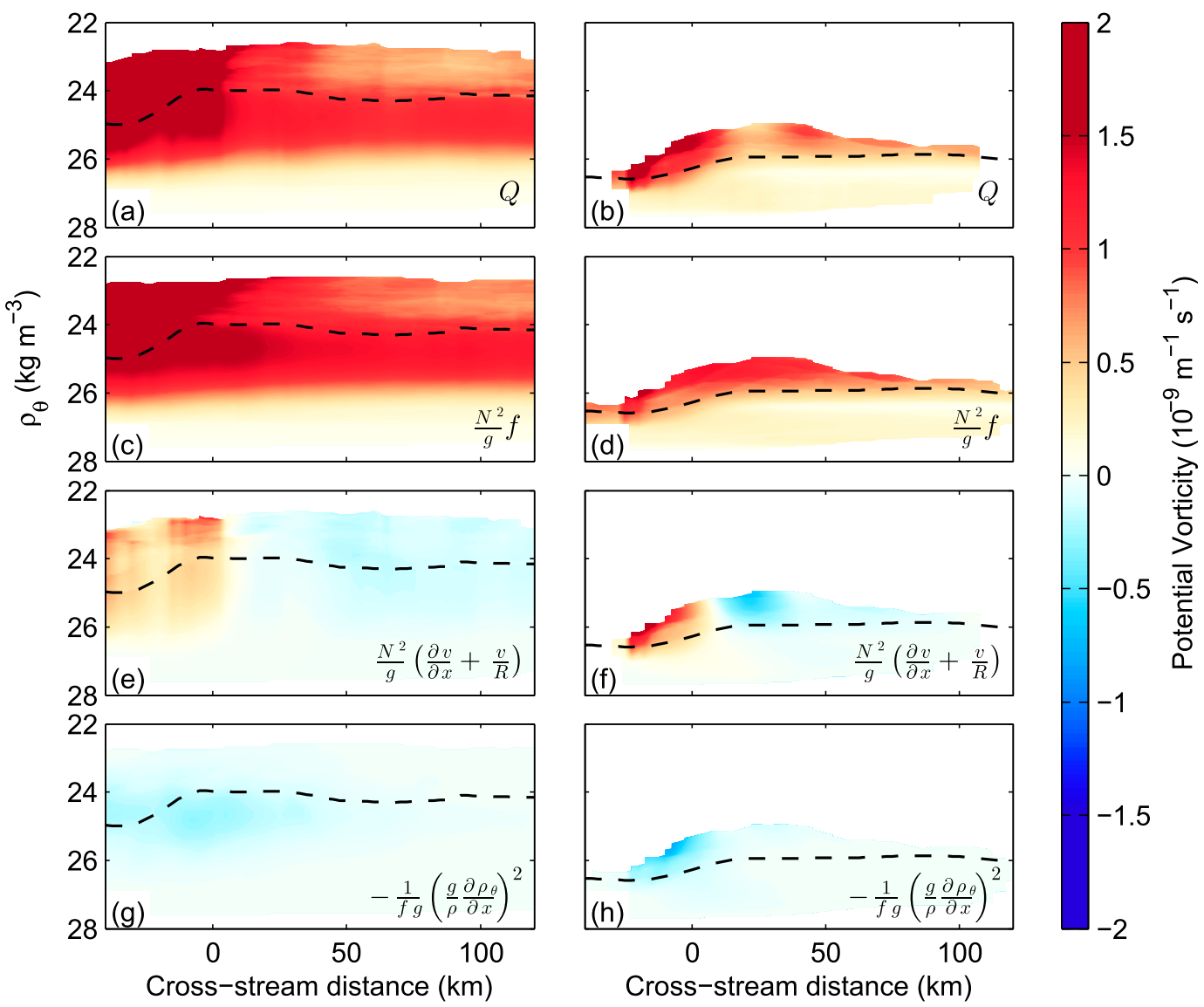

FIG. 12. Mean potential vorticity in the (left) Loop Current and (right) Gulf Stream as functions of potential density and cross-stream position. (a),(b) Total potential vorticity and contributions from (c),(d) the vertical component of the planetary vorticity; (e),(f) the vertical component of the relative vorticity; and (g),(h) the horizontal component of the relative vorticity. Mean values are only shown at positions covered by at least six glider transects. The dashed lines indicate the densest outcropping isopycnal observed at each cross-stream position.

6) were all occupied during fall or early winter, but this apparent seasonality may be an artifact of the relatively few transects across the Gulf Stream.

Caution is warranted in interpreting these glider-based estimates of $\zeta_{\text {abs }}<0$ as observational evidence of centrifugal instability in the western boundary current away from the continental slope. In a realistic numerical simulation, Gula et al. (2015) find centrifugal instabilities in the Gulf Stream only when the current flows along the continental margin. Given the strong constraints on negative absolute vorticity (see Rudnick 2001) and the difficulty in estimating relative vorticity from observations since the second cross-stream derivatives of density must be estimated, it is worth considering how accurate the estimates of large, negative $\zeta_{\text {abs }}$ are. Figures 16a and $16 \mathrm{~b}$ show distributions of glider-based estimates of relative vorticity normalized by the local Coriolis parameter, $\zeta / f$, for the upper $200 \mathrm{~m}$ of the Loop Current and Gulf Stream, respectively. Both distributions are positively skewed, indicating the expected preference for large cyclonic relative vorticity over large anticyclonic vorticity (e.g., Rudnick 2001; Shcherbina et al. 2013); this skewness is apparent in the larger positive tails of the distribution and in the shift of the mode to negative values. Gliderbased estimates of relative vorticity that indicate $\zeta_{\text {abs }}<$ 0 occur rarely; $0.8 \%$ of $\zeta / f$ estimates in the Loop Current and $1.5 \%$ of the estimates in the Gulf Stream are less than -1 (Figs. 16a,b).

To gauge the accuracy of the glider-based estimates of relative vorticity, we can compare their distributions to distributions of similar estimates. Figure 16c shows the distribution of normalized relative vorticity estimates in the vicinity of the Gulf Stream from shipboard ADCP measurements along Line W (Toole et al. 2011). Fiveminute averages of shipboard ADCP data from 13 quasi-synoptic transits along Line $\mathrm{W}$ were rotated to obtain estimates of velocity across Line W, objectively mapped with a 30-km Gaussian length scale, and then differenced along Line $\mathrm{W}$ to produce estimates of one component of the relative vorticity. The distribution of 


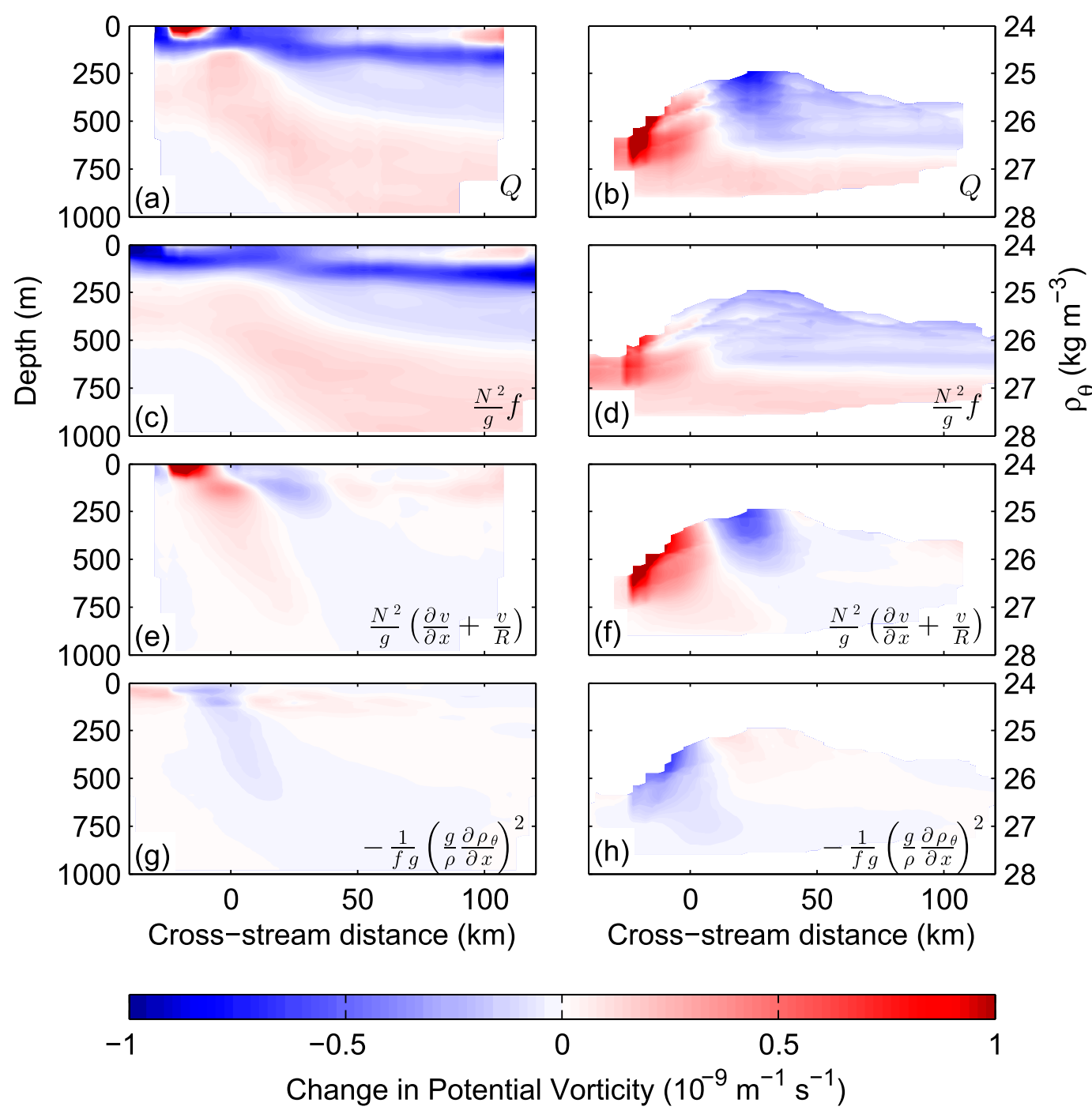

FIG. 13. Changes in (a),(b) mean potential vorticity and (c)-(h) its components between the Loop Current and Gulf Stream. Differences are calculated along both (left) horizontal surfaces and (right) potential density surfaces.

these estimates is also positively skewed, but notably narrower than the distribution of glider-based estimates (standard deviation of 0.23 for Line $\mathrm{W}$ versus 0.45 for the glider-based Gulf Stream estimates); some of this narrowness is attributable to not resolving the full relative vorticity (Rudnick 2001). No estimates of $\zeta / f$ are less than -1 using the Line W observations. Shcherbina et al. (2013, their Fig. 2a) show the distribution of normalized relative vorticity in the upper $50 \mathrm{~m}$ of the water column on the seaward side of the Gulf Stream based on estimates from a two-ship survey that resolved the full horizontal velocity gradient tensor; their distribution is more strongly skewed (skewness of 2.52 versus 1.05 for the glider-based Gulf Stream estimates) and broader (standard deviation of $0.94)$ with notably higher incidence of estimates of $\zeta / f<-1$. Given that the distributions of glider-based estimates of normalized relative vorticity fall in between those from single-ship and two-ship surveys in the region, a conservative interpretation of the glider-based estimates of relative vorticity would be to state that anticyclonic relative vorticity in the western boundary current can have magnitude approaching the local Coriolis parameter, indicating that the flow is at least predisposed to instability; other effects, such as down-front winds (Thomas and Lee 2005) may further destabilize the flow.

\section{3) SYMmetric INSTABILITY}

We find evidence of symmetric instability in $18 \%$ of Loop Current transects (7 out of 40 ) and $36 \%$ of Gulf Stream transects (4 out of 11). Regions with $0<N^{2} \zeta_{\text {abs }}<$ $(1 / f g)\left[(g / \rho)\left(\partial \rho_{\theta} / \partial x\right)\right]^{2}$ are smaller in extent than regions where estimates of $\zeta_{\text {abs }}$ are negative and do not tend to 


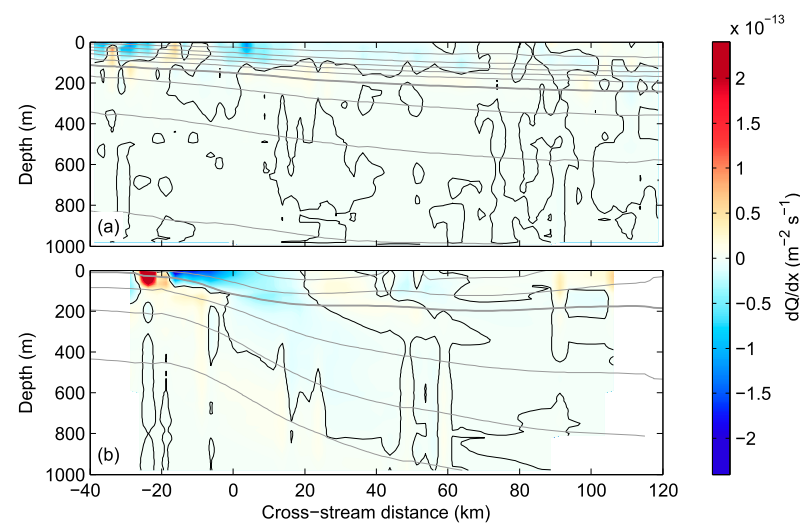

FIG. 14. Cross-stream gradient of mean potential vorticity $d Q / d x$ for the (a) Loop Current and (b) Gulf Stream. The zero contour of the potential vorticity gradient is drawn in black. Contours of mean potential density (gray) are as in Fig. 8.

occur at the same locations in different transects (Figs. 15b,d). With one exception in July 2009, all evidence of symmetric instability in the Loop Current occurred between late October and late March (i.e., during the latter half of fall and winter). In the Gulf Stream, evidence of symmetric instability was found only during fall and early winter (the same transects on which estimates of $\zeta_{\text {abs }}<0$ were found). The occurrence of symmetric instability in fall and winter, when storminduced mixing and reduced solar heating reduce nearsurface stratification, is to be expected from examination of Eq. (3); reduced stratification reduces the magnitude of the vertical components of the planetary and relative vorticities, but does not directly affect the horizontal component of the relative vorticity. Strong mixing to reduce vertical stratification was a prerequisite to observe the formal conditions for symmetric instability, consistent with the comment by Hoskins (1974) that "frictional and heating effects are needed to generate instability to symmetric motions in a previously stable atmosphere."

\section{Summary}

Using a set of high-resolution observations across both the Loop Current and the Gulf Stream collected using autonomous underwater gliders, we have described the hydrographic, velocity, and potential vorticity structure in two segments of the North Atlantic western boundary current. Hydrographic and velocity structure derived from the glider transects agrees well with prior observational results despite the oblique sampling caused by the boundary current speeds substantially
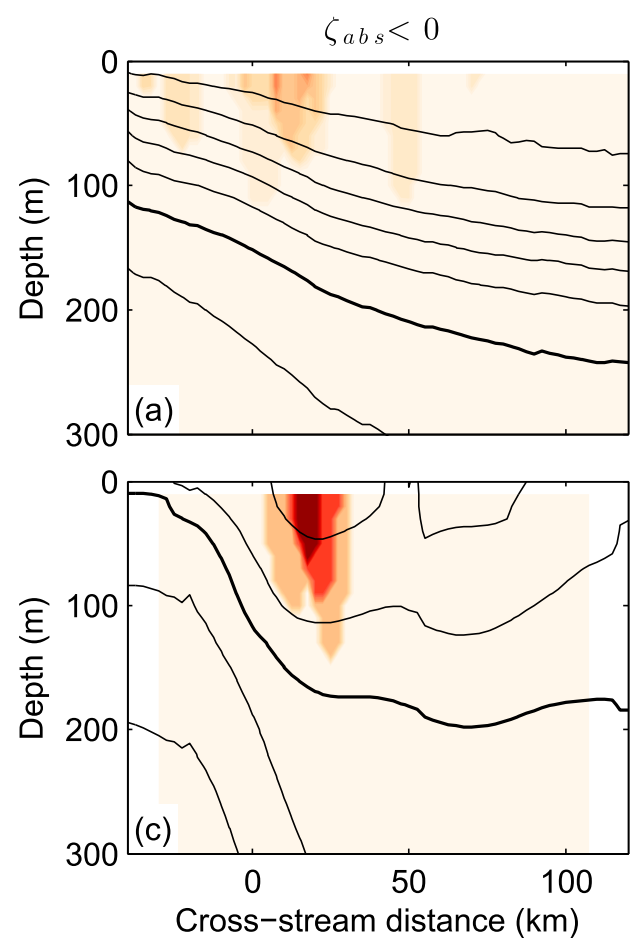

$$
0<N^{2} \zeta_{\mathrm{abs}}<\frac{1}{f g}\left(\frac{g}{\rho} \frac{\partial \rho_{\theta}}{\partial x}\right)^{2}
$$
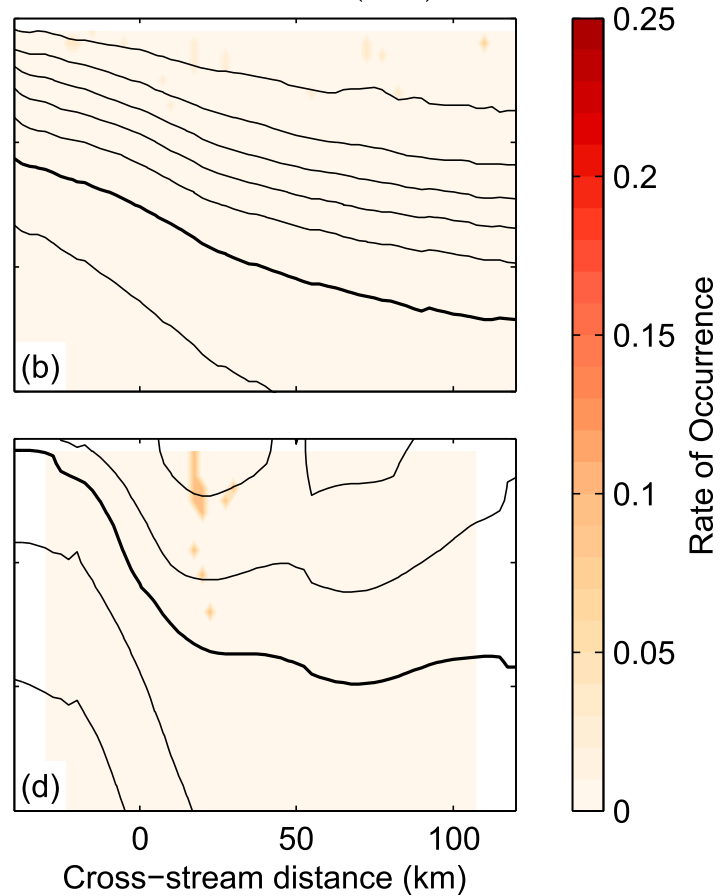

FIG. 15. Rates of occurrence of glider-based estimates of (left) negative absolute vorticity $\zeta_{\text {abs }}$ and (right) $0<$ $N^{2} \zeta_{\text {abs }}<(1 / f g)\left[(g / \rho)\left(\partial \rho_{\theta} / \partial x\right)\right]^{2}$ in the (a),(b) Loop Current and (c),(d) Gulf Stream as a function of depth and crossstream distance. Instability criteria are as defined in the text. Contours of mean potential density (black) are as in Fig. 8. Rate of occurrence is shown only at cross-stream locations with at least six occupations by gliders. 


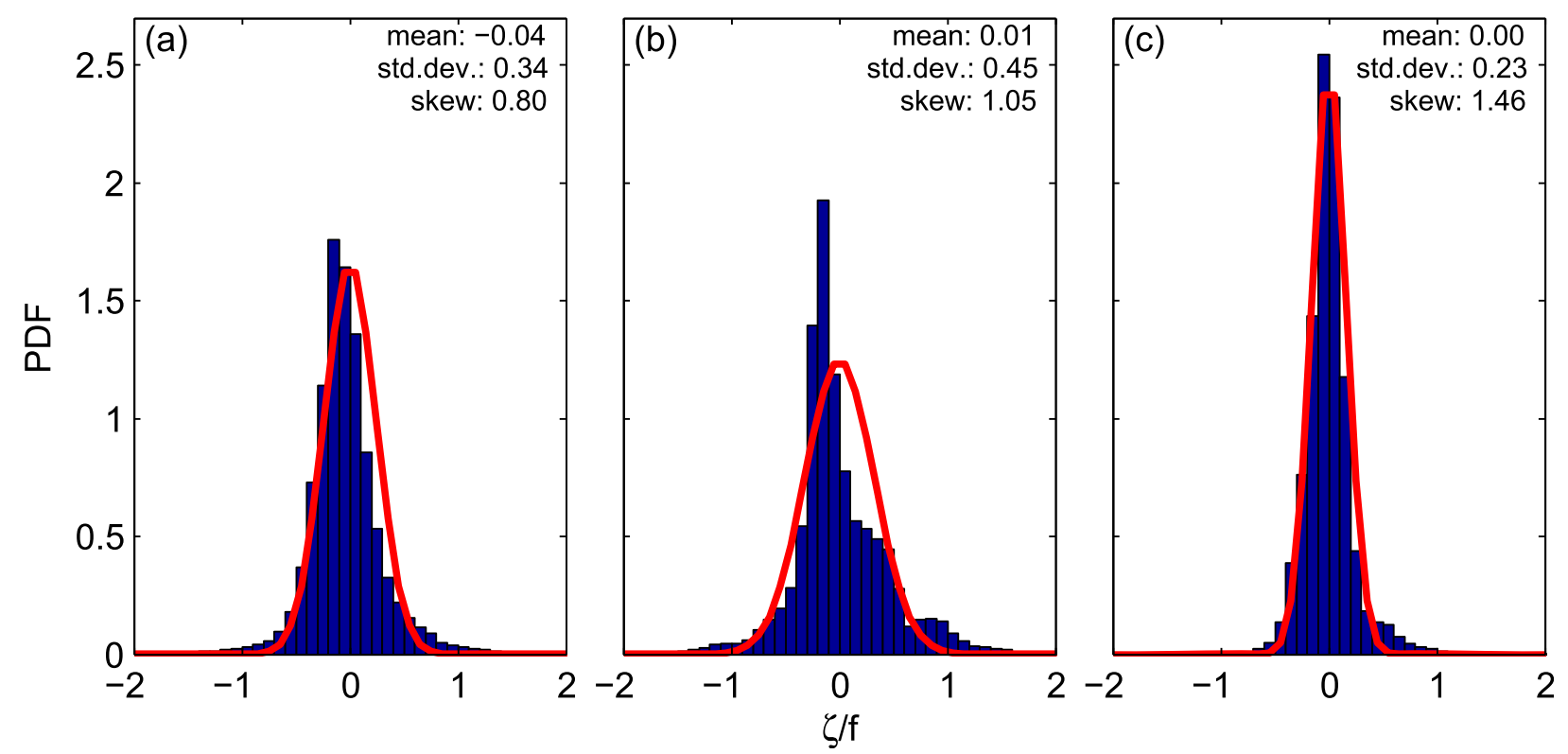

FIG. 16. Probability distribution functions of the vertical component of relative vorticity normalized by the local planetary vorticity $\zeta / f$. Distributions calculated from glider observations in (a) the Loop Current and (b) the Gulf Stream and (c) from shipboard ADCP measurements along Line W between Woods Hole and Bermuda. Only estimates from the upper $200 \mathrm{~m}$ are included in the distributions. Mean, standard deviation, and skewness of the probability density functions are given in each panel. Red curves show Gaussians with zero mean and standard deviation as given.

exceeding the speed of the gliders. The set of concurrent, high-resolution measurements of hydrography and velocity over many glider transects allows us to examine the mean Ertel potential vorticity [Eq. (1)] for the first time in a western boundary current under the assumptions that flow is parallel to the vertically averaged current measured by the gliders and that the flow is in geostrophic balance.

As the western boundary current flows from the Gulf of Mexico into the open North Atlantic, doubles its volume transport, and detaches from the continental margin, its mean hydrographic, velocity, and potential vorticity structure changes markedly (Figs. 8-13). Downstream changes in stratification and planetary vorticity [i.e., the $\left(N^{2} / g\right) f$ term in Eq. (3)] control the sign of these changes in most locations with decreased potential vorticity in the upper layer and increased potential vorticity deeper. An exception to this tendency occurs within the cyclonic side of the current, where enhanced positive relative vorticity in the Gulf Stream above $100 \mathrm{~m}$ leads to an increase in total mean potential vorticity as the western boundary current progresses poleward (Fig. 13). While the observations analyzed here document these differences in structure between two segments of the North Atlantic's western boundary current, the ways in which factors such as changes in latitude, topographic constraints, surface forcing, and eddy fields contribute to the observed changes remain to be explored.
Glider-based estimates of cross-stream potential vorticity structure in the western boundary current highlight the tendency of the current to experience various instabilities. Examination of the cross-stream gradients of mean potential vorticity (Fig. 14) suggests that the western boundary current is susceptible to both barotropic and baroclinic instabilities in both the Gulf of Mexico and downstream of Cape Hatteras in the open North Atlantic. Individual cross-stream transects show susceptibility to overturning instabilities because of very small or negative potential vorticity; many such transects taken together highlight portions of the western boundary current where these instabilities typically occur (Fig. 15).

This study and others conducted in the Pacific (e.g., Rudnick et al. 2011; Davis et al. 2012; Rainville et al. 2013) demonstrate how observations from autonomous underwater gliders can provide long-duration, high-resolution observations within strong boundary currents. Here we have shown how these glider observations can be used to produce estimates of the potential vorticity, a key dynamical property of the North Atlantic western boundary current. Such estimates can serve as targets for efforts to accurately represent western boundary currents in numerical models. Moreover, routine observations by gliders in the western boundary current as part of a sustained boundary current observing system (e.g., Send et al. 

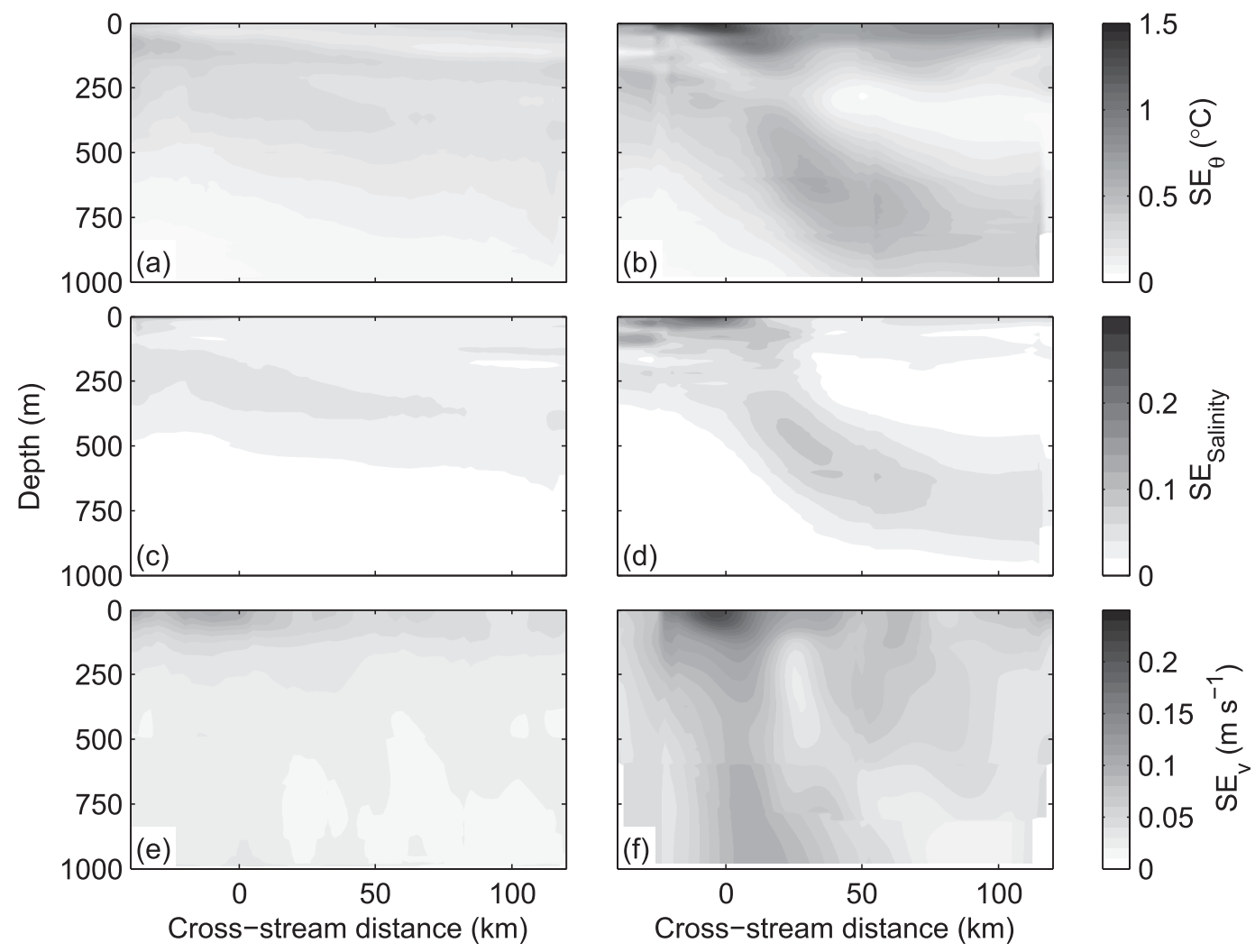

FIG. A1. Standard errors for (a),(b) temperature; (c),(d) salinity; and (e),(f) downstream velocity for the (left) Loop Current and (right) Gulf Stream corresponding to the means shown in Fig. 8.

2010; Testor et al. 2010) will provide real-time, highresolution observations of boundary current structure that can be assimilated into numerical models to improve boundary current representation.

Acknowledgments. Spray glider observations would not have been possible without the Instrument Development Group at the Scripps Institution of Oceanography, particularly Russ Davis and Jeff Sherman. We thank Joe Pedlosky for helpful discussions about vorticity. Glider operations in the Gulf Stream were supported by the National Science Foundation under Grant OCE-0220769. Glider operations in the Gulf of Mexico were supported by BP. R.E.T. was supported by the Penzance Endowed Fund in Support of Assistant Scientists and the Independent Research and Development Program at WHOI.

\section{APPENDIX}

\section{Errors in Mean Fields}

We now consider potential errors in the mean hydrographic and potential vorticity fields generated from glider observations in the Loop Current and Gulf Stream. As a simple measure, we consider the standard error defined at a given depth and cross-stream distance as the standard deviation at that location over multiple mapped transects divided by the square root of the number of transects contributing to the mean and standard deviation at that location. This method of estimating errors neglects contributions from measurement error and from objective mapping of sections. Measurement errors are small; the gliders' CTDs report temperatures and salinities that compare well with coincident measurements (Rudnick and Cole 2011) and show minimal drifts (Davis et al. 2012) (except for the pre-2010 Loop Current deployments described above), while vertically averaged velocities are typically accurate to within $0.01 \mathrm{~m} \mathrm{~s}^{-1}$ (Todd et al. 2011). The objective mapping routine used to place observations from each transect in a common cross-stream coordinate system provides estimates of normalized mean square error, which we require to be less than 0.3. Thus, we assume that temporal and spatial variability between transects that are separated in both time and alongstream position are the leading contributors to uncertainty in our mean fields. 


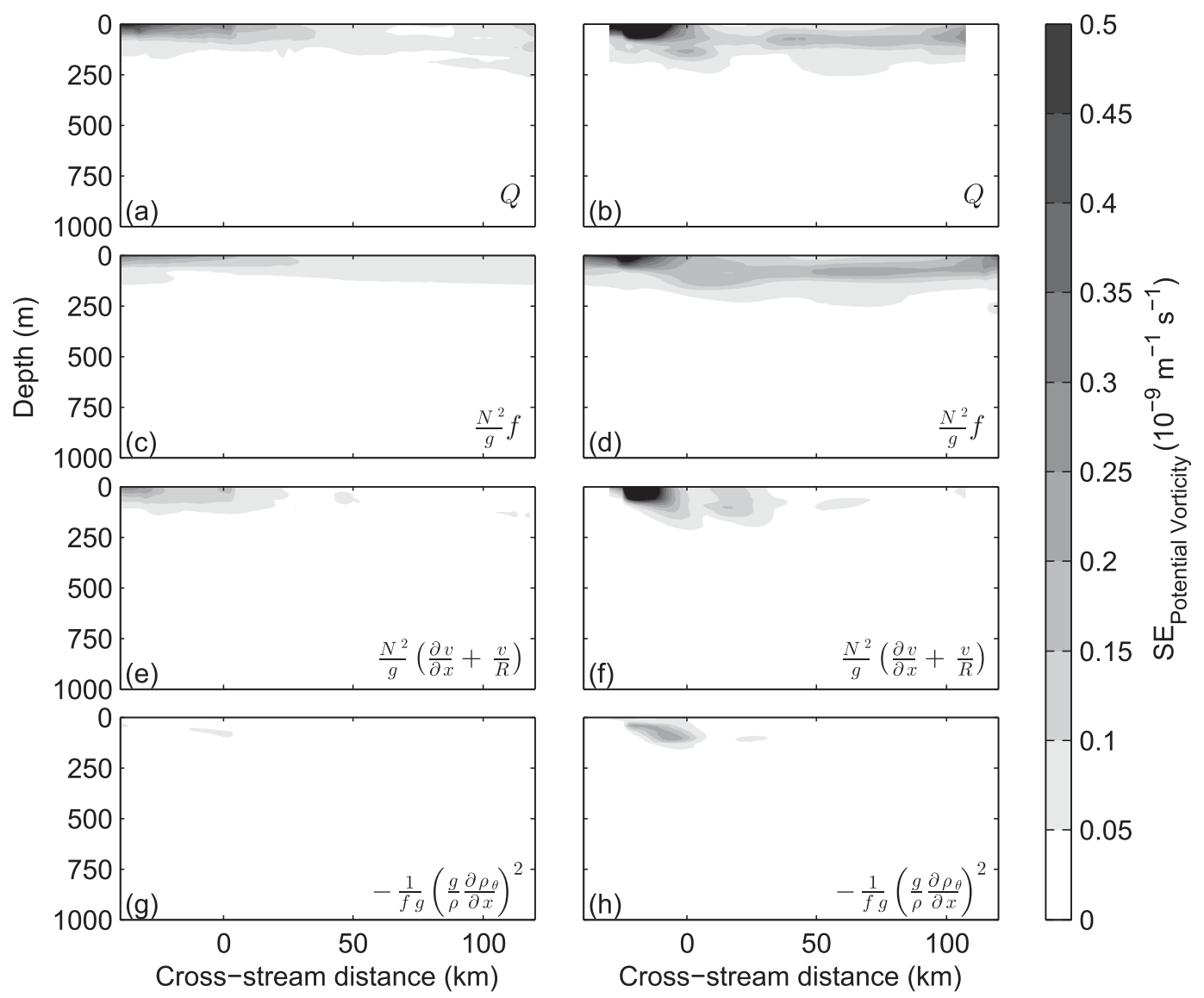

FIG. A2. Standard errors for (a),(b) total potential vorticity and contributions from (c),(d) the vertical component of the planetary vorticity; (e),(f) the vertical component of the relative vorticity, and (g),(h) the horizontal component of the relative vorticity for the (left) Loop Current and (right) Gulf Stream corresponding to the means shown in Fig. 11.

Standard errors of the mean temperature, salinity, and absolute downstream velocity fields for the Loop Current and Gulf Stream are small (Fig. A1). Standard errors are largest where gradients of the associated mean fields (Fig. 8) are largest. Standard errors are larger for the Gulf Stream than the Loop Current since fewer transects contribute to the estimate of the mean. Differing horizontal and vertical extent of individual transects lends some vertical structure to the standard error, particularly for the Gulf Stream.

Standard errors of mean potential vorticity and its components are less than $0.05 \times 10^{-9} \mathrm{~m}^{-1} \mathrm{~s}^{-1}$ below approximately $200 \mathrm{~m}$ for both the Loop Current and Gulf Stream (Fig. A2). In the upper $200 \mathrm{~m}$, standard errors are larger because of variability in stratification (Figs. A2c,d) and relative vorticity (Figs. A2e-h) between transects, but standard errors are typically less than $50 \%$ of the size of means. In the Gulf Stream, where fewer transects are available, maximum standard errors approach $1 \times 10^{-9} \mathrm{~m}^{-1} \mathrm{~s}^{-1}$ near the surface for total potential vorticity and the vertical planetary vorticity (Figs. A2b,d) and approach $1.75 \times$ $10^{-9} \mathrm{~m}^{-1} \mathrm{~s}^{-1}$ for the vertical component of relative vorticity (Fig. A2f), but these standard errors are always less than the magnitudes of the mean values (note that the color bars in Figs. 11 and A2. are saturated). Standard errors of potential vorticity components only exceed the corresponding mean values for near-zero estimates of mean relative vorticity; mean values of both total potential vorticity and the vertical component of the planetary vorticity are significantly different from zero everywhere.

For mean hydrographic and potential vorticity fields along isopycnals (i.e., Figs. 9, 12), standard errors (not shown) show similar structure to those along depth surfaces (Figs. A1, A2), with the most notable difference being elevated standard errors at the lightest densities in the Loop Current due to only transects during the warmest periods exhibiting such low densities and contributing to the mean; standard errors are nevertheless smaller than the magnitudes of the mean values for potential vorticity and its components. 


\section{REFERENCES}

Baringer, M. O., and J. C. Larsen, 2001: Sixteen years of Florida Current transport at $27^{\circ}$ N. Geophys. Res. Lett., 28, 3179-3182, doi:10.1029/2001GL013246.

Bower, A. S., 1989: Potential vorticity balances and horizontal divergence along particle trajectories in Gulf Stream meanders east of Cape Hatteras. J. Phys. Oceanogr., 19, 1669-1681, doi:10.1175/1520-0485(1989)019<1669:PVBAHD>2.0.CO;2.

, H. T. Rossby, and J. L. Lillibridge, 1985: The Gulf StreamBarrier or blender? J. Phys. Oceanogr., 15, 24-32, doi:10.1175/ 1520-0485(1985)015<0024:TGSOB $>2.0$. CO;2.

Candela, J., J. Sheinbaum, J. Ochoa, A. Badan, and R. Leben, 2002: The potential vorticity flux through the Yucatan Channel and the Loop Current in the Gulf of Mexico. Geophys. Res. Lett., 29, 2059, doi:10.1029/2002GL015587.

Cenedese, C., R. E. Todd, G. G. Gawarkiewicz, W. B. Owens, and A. Y. Shcherbina, 2013: Offshore transport of shelf waters through interaction of vortices with a shelfbreak current. J. Phys. Oceanogr., 43, 905-919, doi:10.1175/JPO-D-12-0150.1.

Csanady, G. T., and P. Hamilton, 1988: Circulation of slopewater. Cont. Shelf Res., 8 (5-7), 656-624.

Cunningham, S. A., and Coauthors, 2007: Temporal variability of the Atlantic Meridional Overturning Circulation at $26.5^{\circ} \mathrm{N}$. Science, 317, doi:10.1126/science.1141304.

Davis, R. E., C. C. Eriksen, and C. P. Jones, 2003: Autonomous buoyancy-driven underwater gliders. Technology and Applications of Autonomous Underwater Vehicles, G. Griffiths, Ed., Taylor and Francis, 37-58.

_ W. W. Kessler, and J. T. Sherman, 2012: Gliders measure western boundary current transport from the South Pacific to the equator. J. Phys. Oceanogr., 42, 2001-2013, doi:10.1175/JPO-D-12-022.1.

Ertel, H., 1942a: Ein neuer hydrodynamischer Wirbelsatz. Meteor. Z., 59 (9), 277-282.

_ 1942b: Ein neuer hydrodynamischer Erhaltungssatz. Naturwissenschaften, 30 (36), 543-544, doi:10.1007/BF01475602.

Ezer, T., L. P. Atkinson, W. B. Corlett, and J. L. Blanco, 2013: Gulf Stream's induced sea level rise and variability along the U.S. mid-Atlantic coast. J. Geophys. Res. Oceans, 118, 685-697, doi:10.1002/jgrc. 20091.

Fuglister, F. C., and A. D. Voorhis, 1965: A new method of tracking the Gulf Stream. Limnol. Oceanogr., 10 (Suppl.), R115-R124, doi:10.4319/1o.1965.10.suppl2.r115.

Gawarkiewicz, G. G., R. E. Todd, A. J. Plueddemann, M. Andres, and J. P. Manning, 2012: Direct interaction between the Gulf Stream and the shelfbreak south of New England. Sci. Rep., 2, 553, doi:10.1038/srep00553.

Gill, A. E., 1982: Atmosphere-Ocean Dynamics. International Geophysics Series, Vol. 30, Academic Press, 662 pp.

Gopalakrishnan, G., B. D. Cornuelle, and I. Hoteit, 2013: Adjoint sensitivity studies of loop current and eddy shedding in the Gulf of Mexico. J. Geophys. Res. Oceans, 118, 3315-3335, doi:10.1002/jgrc. 20240.

Gula, J., M. J. Molemaker, and J. C. McWilliams, 2015: Gulf Stream dynamics along the southeastern U.S. seaboard. J. Phys. Oceanogr., 45, 690-715, doi:10.1175/ JPO-D-14-0154.1.

Halkin, D. T., and H. T. Rossby, 1985: The structure and transport of the Gulf Stream at $73^{\circ}$ W. J. Phys. Oceanogr., 15, 1439-1452, doi:10.1175/1520-0485(1985)015<1439:TSATOT>2.0.CO;2.

Holton, J. R., 1979: An Introduction to Dynamic Meteorology. 2nd ed. International Geophysics Series, Vol. 23, Academic Press, $391 \mathrm{pp}$.
Hoskins, B. J., 1974: The role of potential vorticity in symmetric stability and instability. Quart. J. Roy. Meteor. Soc., 100, 480482, doi:10.1002/qj.49710042520.

IPCC, 2007: Climate Change 2007: The Physical Science Basis. Cambridge University Press, 996 pp.

Johns, W. E., 1988: One-dimensional baroclinically unstable waves on the Gulf Stream potential vorticity gradient near Cape Hatteras. Dyn. Atmos. Oceans, 11, 323-350, doi:10.1016/ 0377-0265(88)90005-X.

— T. J. Shay, J. M. Bane, and D. R. Watts, 1995: Gulf Stream structure, transport, and recirculation near $68^{\circ} \mathrm{W}$. J. Geophys. Res., 100, 817-838, doi:10.1029/94JC02497.

Joyce, T. M., L. N. Thomas, and F. Bahr, 2009: Wintertime observations of Subtropical Mode Water formation within the Gulf Stream. Geophys. Res. Lett., 36, L02607, doi:10.1029/ 2008 GL035918.

- — - W. K. Dewar, and J. B. Girton, 2013: Eighteen Degree Water formation within the Gulf Stream during CLIMODE. Deep-Sea Res. II, 91, 1-10, doi:10.1016/j.dsr2.2013.02.019.

Le Hénaff, M., V. H. Kourafalou, Y. Morel, and A. Srinivasan, 2012: Simulating the dynamics and intensification of cyclonic Loop Current frontal eddies in the Gulf of Mexico. J. Geophys. Res., 117, C02034, doi:10.1029/2011JC007279.

Logoutov, O., G. Sutyrin, and D. R. Watts, 2001: Potential vorticity structure across the Gulf Stream: Observations and a PVgradient model. J. Phys. Oceanogr., 31, 637-644, doi:10.1175/ 1520-0485(2001)031<0637:PVSATG $>2.0 . \mathrm{CO} ; 2$.

Marshall, J., and Coauthors, 2009: The Climode field campaign: Observing the cycle of convection and restratification over the Gulf Stream. Bull. Amer. Meteor. Soc., 90, 1337-1350, doi:10.1175/2009BAMS2706.1.

Maze, G., J. Deshayes, J. Marshall, A.-M. Tréguier, A. Chronis, and L. Vollmer, 2013: Surface vertical PV fluxes and subtropical mode water formation in an eddy-resolving numerical model. Deep-Sea Res. II, 91, 128-138, doi:10.1016/ j.dsr2.2013.02.026.

McCartney, M. S., 1982: The subtropical recirculation of Mode Waters. J. Mar. Res., 40 (Suppl.), 427-464.

Oey, L.-Y., 2004: Vorticity flux through the Yucatan Channel and Loop Current variability in the Gulf of Mexico. J. Geophys. Res., 109, C10004, doi:10.1029/2004JC002400.

Olsina, O., N. Wienders, and W. K. Dewar, 2013: An estimate of the climatology and variability of Eighteen Degree Water potential vorticity forcing. Deep-Sea Res. II, 91, 84-95, doi:10.1016/j.dsr2.2013.02.018.

Owens, W. B., and A. P. S. Wong, 2009: An improved calibration method for the drift of the conductivity sensor on autonomous CTD profiling floats by $\theta-S$ climatology. Deep-Sea Res. I, 56, 450-457, doi:10.1016/j.dsr.2008.09.008.

Pedlosky, J., 1964: The stability of currents in the atmosphere and the ocean: Part 1. J. Atmos. Sci., 21, 201-219, doi:10.1175/ 1520-0469(1964)021<0201:TSOCIT>2.0.CO;2.

Qu, T., S. Gao, and I. Fukumori, 2013: Formation of salinity maximum water and its contribution to the overturning circulation in the North Atlantic as revealed by a global general circulation model. J. Geophys. Res., 118, 1982-1994, doi:10.1002/ jgrc.20152.

Rainville, L., C. M. Lee, D. L. Rudnick, and K.-C. Yang, 2013: Propagation of internal tides generated near Luzon Strait: Observations from autonomous gliders. J. Geophys. Res. Oceans, 118, 4125-4138, doi:10.1002/jgrc.20293.

Rajamony, J., D. Hebert, and H. T. Rossby, 2001: The cross-stream potential vorticity front and its role in meander-induced 
exchange in the Gulf Stream. J. Phys. Oceanogr., 31, 3551-3568, doi:10.1175/1520-0485(2001)031<3551:TCSPVF>2.0.CO;2.

Rossby, T., and H.-M. Zhang, 2001: The near-surface velocity and potential vorticity structure of the Gulf Stream. J. Mar. Res., 59, 949-975, doi:10.1357/00222400160497724.

, C. N. Flagg, K. A. Donohue, A. Sanchez-Franks, and J. Lillibridge, 2014: On the long-term stability of Gulf Stream transport based on 20 years of direct measurements. Geophys. Res. Lett., 41, 114-120, doi:10.1002/2013GL058636.

Rudnick, D. L., 2001: On the skewness of vorticity in the upper ocean. Geophys. Res. Lett., 28, 2045-2048, doi:10.1029/2000GL012265.

— , and S. T. Cole, 2011: On sampling the ocean using underwater gliders. J. Geophys. Res., 116, C08010, doi:10.1029/ 2010JC006849.

— R. E. Davis, C. C. Eriksen, D. M. Fratantoni, and M. J. Perry, 2004: Underwater gliders for ocean research. Mar. Technol. Soc. J., 38, 73-84, doi:10.4031/002533204787522703.

— the Kuroshio near its origin. Oceanography, 24, 52-63, doi:10.5670/oceanog.2011.94.

— T. M. S. Johnston, and J. T. Sherman, 2013: High-frequency internal waves near the Luzon Strait observed by underwater gliders. J. Geophys. Res. Oceans, 118, 774-784, doi:10.1002/jgrc.20083.

- , G. Gopalakrishnan, and B. D. Cornuelle, 2015: Cyclonic eddies in the Gulf of Mexico: Observations by underwater gliders and simulations by numerical model. J. Phys. Oceanogr., 45, 313-326, doi:10.1175/JPO-D-14-0138.1.

Salmon, R., 1998: Lectures on Geophysical Fluid Dynamics. Oxford University Press, $378 \mathrm{pp}$.

Schubert, W., E. Ruprecht, R. Hertenstein, R. Ferreira, R. Taft, C. Rozoff, P. Ciesielski, and H.-C. Kuo, 2004: English translations of twenty-one of Ertel's papers on geophysical fluid dynamics. Meteor. Z., 13, 527-576, doi:10.1127/0941-2948/ 2004/0013-0527.

Send, U., and Coauthors, 2010: A global boundary current circulation observing network. Proceedings of OceanObs'09: Sustained Ocean Observations and Information for Society, Vol. 2, J. Hall, D. E. Harrison, and D. Stammer, Eds., ESA Publ. WPP-306, European Space Agency, doi:10.5270/ OceanObs09.cwp.78.

Shcherbina, A. Y., E. A. D'Asaro, C. M. Lee, J. M. Klymak, M. J. Molemaker, and J. C. McWilliams, 2013: Statistics of vertical vorticity, divergence, and strain in a developed submesoscale turbulence field. Geophys. Res. Lett., 40, 4706-4711, doi:10.1002/grl.50919.

Sheinbaum, J., J. Candela, A. Badan, and J. Ochoa, 2002: Flow structure and transport in the Yucatan Channel. Geophys. Res. Lett., 29, 1040, doi:10.1029/2001GL013990.
Sherman, J., R. E. Davis, W. B. Owens, and J. Valdes, 2001: The autonomous underwater glider "Spray". IEEE J. Oceanic Eng., 26, 437-446, doi:10.1109/48.972076.

Song, T., and H. T. Rossby, 1997: Analysis of Lagrangian potential vorticity balance and lateral displacement of water parcels in Gulf Stream meanders. J. Phys. Oceanogr., 27, 325-339, doi:10.1175/1520-0485(1997)027<0325: AOLPVB $>2.0 . \mathrm{CO} ; 2$.

Testor, P., and Coauthors, 2010: Gliders as a Component of Future Observing Systems. Proceedings of OceanObs'09: Sustained Ocean Observations and Information for Society, Vol. 2, J. Hall, D. E. Harrison, and D. Stammer, Eds., ESA Publ. WPP-306, European Space Agency, doi:10.5270/ OceanObs09.cwp.89.

Thomas, L. N., 2005: Destruction of potential vorticity by winds. J. Phys. Oceanogr., 35, 2457-2466, doi:10.1175/JPO2830.1.

_ 2007: Dynamical constraints on the extreme low values of the potential vorticity in the ocean. Extreme Events: Proc. 'Aha Huliko'a Hawaiian Winter Workshop, Honolulu, HI, University of Hawai'i at Mānoa, 1-8.

_ front winds. J. Phys. Oceanogr., 35, 1086-1102, doi:10.1175/ JPO2737.1.

_ and T. M. Joyce, 2010: Subduction on the northern and southern flanks of the Gulf Stream. J. Phys. Oceanogr., 40, 429-438, doi:10.1175/2009JPO4187.1.

— J. R. Taylor, R. Ferrari, and T. M. Joyce, 2013: Symmetric instability in the Gulf Stream. Deep-Sea Res. II, 91, 96-110, doi:10.1016/j.dsr2.2013.02.025.

Todd, R. E., D. L. Rudnick, M. R. Mazloff, R. E. Davis, and B. D. Cornuelle, 2011: Poleward flows in the southern California Current System: Glider observations and numerical simulation. J. Geophys. Res., 116, C02026, doi:10.1029/2010JC006536.

Toole, J. M., R. G. Curry, T. M. Joyce, M. McCartney, and B. Peña Molino, 2011: Transport of the North Atlantic Deep Western Boundary Current about $39^{\circ} \mathrm{N}, 70^{\circ} \mathrm{W}: 2004-2008$. Deep-Sea Res. II, 58, 1768-1780, doi:10.1016/j.dsr2.2010.10.058.

Vukovich, F. M., 2007: Climatology of ocean features in the Gulf of Mexico using satellite remote sensing data.J. Phys. Oceanogr., 37, 689-707, doi:10.1175/JPO2989.1.

Worthington, L. V., 1959: The $18^{\circ}$ water in the Sargasso Sea. DeepSea Res., 5, 297-305, doi:10.1016/0146-6313(58)90026-1.

Wright, D. G., 1981: Baroclinic instability in Drake Passage. J. Phys. Oceanogr., 11, 231-246, doi:10.1175/1520-0485(1981)011<0231: BIIDP $>2.0 . \mathrm{CO} ; 2$.

Wyrtki, K., L. Magaard, and J. Hager, 1976: Eddy energy in the oceans. J. Geophys. Res., 81, 2641-2646, doi:10.1029/ JC081i015p02641. 